Check for updates

Cite this: Mater. Adv., 2021, 2,5803

Received 1st May 2021,

Accepted 9th August 2021

DOI: 10.1039/d1ma00400j

rsc.li/materials-advances

\section{Construction of spatially organized, peptide/ peptide derivative containing nanocomposites}

\author{
Mingyang $\mathrm{Ji}$ (D) and Zhaoyang Liu
}

\begin{abstract}
The functioning of naturally occurring materials and organisms emerges from the synergistic actions of all involved functional subunits following well-defined spatial hierarchies. Resembling the exquisite structure of biological machinery, the hierarchical organization of synthetic materials over a continuum of length scales and complexity dictates their functional competence. To replicate the structure-function relationships of natural origin materials, peptide-based building blocks capable of spontaneous association have been exploited to construct nanocomposites inherent with precise spatial order and biocompatibility. Moreover, the evolving functionalities of synthetic materials necessitate higher-order chemical diversity and structural complexity, accordingly, additional components have been coupled with peptidic nanoassemblies to achieve hierarchical multicomponent nanocomposites. This review starts with a brief introduction of kinetic and thermodynamic principles of supramolecular polymerization and these principles largely direct the construction of nanostructures containing amphiphilic peptides or peptide derivatives as well. Taking the synergism of kinetic factors and thermodynamic preferences as a guide, we critically review various strategies to construct spatially organized, multicomponent nanocomposites. All these strategies similarly involve amphiphilic building blocks consisting of assembling peptide domains that contribute to the generation of supramolecular frameworks allowing the incorporation of functional chromophores/constituents with nanoscale precision. Nanocomposites integrated with multiple components give access to greater structural tunability and complexity to perform complex tasks, thereby exerting usage in biomedical formulations and energy harvesting and conversion.
\end{abstract}

\section{Introduction}

Naturally occurring materials and organisms contain multiple functional subunits whose spatial arrangements dictate their synergistic actions to perform complex tasks. ${ }^{1}$ To fully replicate the functional competence of biological machinery, emerging research on synthetic materials has been focused on the construction of multicomponent nanocomposites whose diversity in chemical composition may give access to the hierarchical arrangement within resulting materials. ${ }^{2,3}$ Resembling the sophisticated structural organization of archetypes with natural origin, evolving functionalities of synthetic materials impose unprecedented requirements on their structural regulation with nanoscale precision. Therefore, peptides, the basic subsegments of proteins that can spontaneously associate into various nanostructures through reversible and directional noncovalent interactions, have been employed to construct supramolecular architectures. $^{4-7}$ Given the versatile surface of peptidic assemblies capable of various noncovalent interactions, they can serve as supramolecular templates to incorporate

Research School of Polymeric Materials, School of Materials Science \& Engineering, Jiangsu University, Zhenjiang 212013, China. E-mail: jimy@ujs.edu.cn additional components and thus to achieve integrative, multicomponent nanostructures with well-defined spatial hierarchy. ${ }^{8}$ Moreover, with the inherent biocompatibility of peptide frameworks, these peptidic nanocomposites may bridge the gap between organic and inorganic regimes, ${ }^{9}$ thus exerting usage in disparate fields ranging from biomedical formulations ${ }^{10-12}$ to energy conversion and storage devices. ${ }^{4,13,14}$ The purpose of this review is to survey strategies to construct nanostructures from amphiphilic building blocks, particularly from amphiphilic peptides and/or peptide derivatives. In addition, resulting nanostructures can serve as supramolecular frameworks to regulate the incorporation of other functional components in nanoscale precision, thereby producing multicomponent nanocomposites with a welldefined spatial organization. To fully reflect advances in the preparation of well-defined nanostructures involving assembling peptide factors, nanocomposites discussed in this review are not restricted to pure peptide/peptide derivative assemblies but encompass complex hybrids that may also contain proteins, oligonucleotides, polymers, carbon nanotube, even metallic additives. The task execution of these multicomponent nanocomposites that closely correlates with the spatial arrangement of functional constituents is highlighted as well. 
The desirable functioning of living systems, such as photosynthesis and immune response, depends on the synergism of multiple subunits integrated within biological structures with a finely tuned spatial arrangement. ${ }^{15}$ For example, adenosine triphosphate (ATP) synthase consists of two subunits, $\mathrm{F}_{\mathrm{O}}$ and $\mathrm{F}_{1}$, working in a rotational motor mechanism to produce energy storage molecules ATP. Within the ATP synthase, the spinning of its $\mathrm{F}_{\mathrm{O}}$ region, driven by the proton $\left(\mathrm{H}^{+}\right)$concentration gradient in the cellular environment, causes the conformational changes of its $F_{1}$ region, which propel the dehydration between adenosine diphosphate (ADP) and inorganic phosphate to yield ATP. As $F_{O}$ and $\mathrm{F}_{1}$ regions act in concert, ATP synthase store energy for the consumption of living cells in ATP molecules consecutively. ${ }^{16,17}$ Inspirations from biological machinery motivates the preparation of functional nanomaterials by spatially integrating monomeric building blocks into well-defined nanostructures. ${ }^{18}$ However, the structural complexity of current artificial nanoassemblies is still hardly comparable with the exquisite organization of biological machinery, which compromises their functional competence to perform structure-determined complex tasks. Therefore, integrating multiple components into one comprehensive, hierarchical structure with nanoscale precision has garnered growing attention, as the chemical diversity of such multicomponent nanostructures may contribute to a larger structural tunability and complexity to replicate natural processes.

Nanocomposites consisting of multiple components may provide access to emerging properties that cannot be achieved by individual components acting in isolation. ${ }^{8,19}$ For instance, through the orthogonal assembly of electron donors (D) and acceptors (A), individually continuous electron-sufficient and deficient channels can be produced and brought into intimate contact to construct the supramolecular $\mathrm{p}$-/n-heterojunction $(\mathrm{SHJ}){ }^{20,21}$ At the $\mathrm{D} / \mathrm{A}$ interface within $\mathrm{SHJ}$, photo-generated excitons quickly dissociate into charge carriers as electrons and holes that transport to corresponding electrodes to produce the photocurrent. ${ }^{22}$ While segregated $\mathrm{D}$ and A domains in close proximity are indispensable to achieve efficient photoinduced charge separation, strong charge-transfer interactions between D-A pairs can be detrimental for the preferential recognition of self-species during the orthogonal assembly of D-A mixture, thus resulting in the formation of their alternating stacks instead. ${ }^{23,24}$ To circumvent this undesirable alternating complexation, D and A chromophores are conjugated with additional segments capable of highly tunable association, such as peptides or peptide derivatives, ${ }^{5,25}$ to mitigate the charge-transfer interactions between D-A pairs. By tailoring the peptide sequence, attractive and repulsive interactions can be programmed into $\mathrm{D} / \mathrm{A}$-peptide conjugates, which enable the construction of well-defined nanostructures integrated with segregated domains that synergistically act to produce a higher level of functional competence. ${ }^{26,27}$

The hierarchical organization of multicomponent structures closely correlates with self-sorting, a phenomenon that produces preferential homo-/hetero-association of monomers within a multi-component mixture (Fig. 1). ${ }^{28}$ According to the potential energy of the assembling system, self-sorting can be

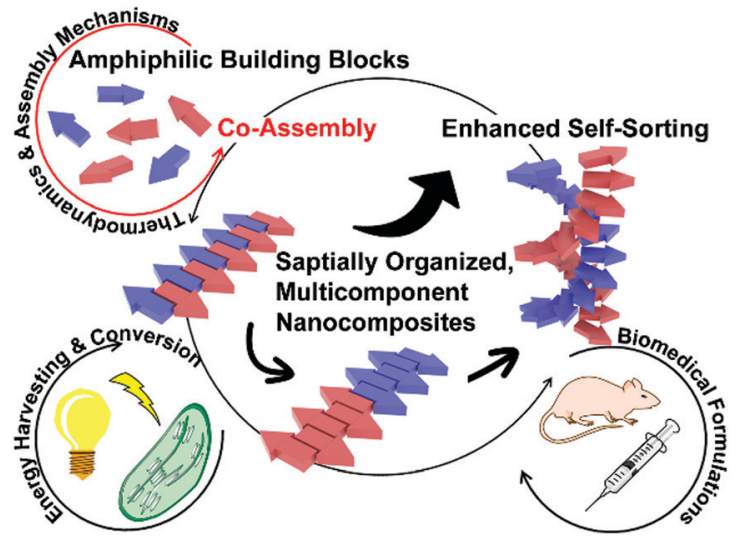

Fig. 1 Co-assembly of amphiphilic building blocks, including peptides and peptide derivatives. A scheme illustrates the positioning of sorted subunits within multicomponent nanostructures that may induce structural synergism, which impacts the functioning of the resulting materials.

achieved under thermodynamic or kinetic control. While most early self-sorting studies are under thermodynamic control, ${ }^{28,29}$ kinetic factors such as time, temperature and concentration have been recognized as decisive conditions to achieve heterogeneous microstructures integrated with sorted components. ${ }^{30-33}$ Given the complex synergism of kinetic and thermodynamic preferences during multi-component assembly, the construction of nanocomposites with well-defined spatial organization necessitates a thorough understanding of the fundamental mechanisms of molecular self-assembly. Multicomponent assembly shares fundamental concepts and well-established theories with single-component systems, although the simultaneous involvement of several types of monomers inevitably diversifies the assembly pathway. ${ }^{19,23}$ The Gibbs free energy $(\Delta G)$ of growing assemblies evolves with the addition of each monomer, ${ }^{32,34-36}$ and theoretical models deriving from $\Delta G$ along with monomer association give rise to assembly mechanisms as isodesmic, cooperative and anti-cooperative. ${ }^{30,34,35,37-41}$ Although multicomponent systems bear more variabilities on their pathway selection, theories of single component assembly may still be instructional, especially given that each respective component in the assembling mixture can be separately integrated into the growing nanostructure in a stepwise manner. ${ }^{42-46}$ Studies on thermodynamics and mechanisms of monomer association have deepened our understanding of the intrinsic physical aspects of self-assembly and motivate multicomponent co-assembly toward designable and predictable patterns.

Peptides typically comprise 2-50 amino acid residues and serve as the most common sub-segments of proteins. ${ }^{1,47,48}$ Through well-established solid-phase synthesis, various residues with ionizable or aromatic pendants can be precisely programmed into the peptide sequence, thus imparting positive/ negative, polar/non-polar sites to peptides. ${ }^{47,48}$ The highly designable sequence of peptides renders them versatile building blocks capable of hydrophobic, electrostatic, hydrogen bonding, or van der Waals interactions, and these abundantly available interactions motivate peptides to assemble into $\alpha$-helices, 
$\beta$-sheets, and other higher-order protein complexes. Also, the integrity of resulting peptide-based constructs is maintained by non-covalent interactions, ${ }^{49,50}$ which generates the adaptable structure of assembled peptides sensitive to physiological changes including temperature, $\mathrm{pH}$, ionic strength, etc. ${ }^{4,51}$ The programmability of peptide sequences and the structural flexibility of peptide assemblies toward potential physiological cues permit the versatile applications of peptide derivatives in nanotherapies. Moreover, dimensions of peptide-based constructs cover a continuum of length scales ranging from nanoparticles, nanotubes to micrometer-long fibers and injectable bulk hydrogels, which suggest their applications beyond the cellular level. ${ }^{52}$ Recently, peptidic assemblies have been utilized to construct the device-tissue interfaces where biocompatibility is highly desirable. ${ }^{4}$ Given the natural origin of assembling peptides, they have been explored to bridge the gap between innovative bio-products and traditional electronic devices.

This review survey strategies to integrate multiple components, mostly including amphiphilic peptides or peptide derivatives, into one nanostructure to produce spatially organized nanocomposites. The spatial arrangement of functional subunits establishes the sophisticated function of biomolecules, likewise, the precise integration of segregated domains into one comprehensive structure determines the performance of artificial nanomaterials. In order to achieve the fidelity binding between desired species within a complex mixture of monomers, a thorough understanding of the mechanistic aspects of supramolecular self-assembly becomes highly desirable. There are some in-depth reviews that illustrate the assembly mechanisms of synthetic building blocks and the applications of relevant materials across various fields. $^{23,32,34,35,37}$ Instead of giving an exhaustive compilation of existing works, our discussion starts from the fundamental kinetic and thermodynamic principles of supramolecular polymerization. While these principles arise from studies on pure synthetic systems, they are of use in guiding the assembly of amphiphilic building blocks with natural origins, such as peptides or peptide derivatives. Taking the mechanistic aspects of supramolecular selfassembly into consideration, we critically review some innovative strategies to construct multi-component nanocomposites whose spatial organization is largely influenced or entirely directed by assembling peptide domains. Following these co-assembly strategies wherein every individual component is finely positioned with nanoscale precision, the task execution of resulting nanocomposites that requires the synergistic action of all functional constituents is presented.

\section{Mechanistic aspects in supramolecular polymerizations}

Supramolecular self-assembly involves spontaneous monomer association that can be either more enthalpy- or entropy-driven. Comparing with synthetic monomers performing organization in apolar environments, the self-assembly of amphiphilic building with natural origin, including amphiphilic peptides and peptide derivatives, usually results from the synergistic action of hydrophilic and hydrophobic domains, which produces its unique thermodynamic preference deviated from typical synthetic systems. ${ }^{31,53-55}$ While amphiphilic systems discussed in this review exhibit special entropic tendencies during monomer association, their assembly processes are still subjected to the same kinetic factors also encountered by synthetic monomers. Therefore, the growth mechanism of supramolecular polymerization, in particular the cooperative mechanism, may still apply to the description of amphiphilic systems and guide the pathway control of peptide/peptide derivative involved assembly.

This section starts from the comparative discussion on various growth mechanisms of supramolecular polymerization. To coordinate with later examples involved, the molecular origin, the rationale of monomer design, available kinetic interventions, and characteristic experimental phenomena of cooperative assembly are highlighted. In addition, our discussion about the cooperative mechanism is coupled with associated pathway complexity, which completes the necessary theoretical context for the following examination on assembling events involving peptide factors. Finally, we combine well-established theories of peptide assembly with the thermodynamic considerations of amphiphilic peptides and peptide derivatives. Despite the differences in intrinsic thermodynamics, the cooperative mechanism arising from synthetic systems can be used to interpret the seeding assembly of peptide derivatives, supported by examples at the end of this section.

\subsection{Growth mechanisms of supramolecular polymerization}

The self-assembly of peptide-based building blocks shares fundamental concepts and theories with general supramolecular monomer associations. The well-documented, quasi-onedimensional assembly growth can be simplified as chain propagation to generate theoretical models of monomer association. Due to their resemblance to covalent polymerization, these spontaneous association processes are referred to as supramolecular polymerization and the growth mechanisms are generally categorized as isodesmic, cooperative and anticooperative. ${ }^{30,31,34,35}$ Isodesmic assembly is characterized by the monomer association that is energetically identical and independent of the degree of aggregation (Fig. 2a). For synthetic monomers governed by the isodesmic mechanism, their assembly usually involves a single type of non-covalent interaction and no steric hindrance due to crowded monomers builds up throughout the assembly process. $^{32}$ In contrast to the identical binding constant of each monomer addition of isodesmic mechanism, cooperative and anti-cooperative processes follow the nucleationelongation model, which has a smaller (for cooperative mechanism) or larger (for anti-cooperative mechanism) association constant of nucleation than that of elongation. ${ }^{34,56}$ The anti-cooperative process usually emerges from an energetically favorable dimerization or oligomerization at the initial stage of assembly, which is subsequently coupled with steric congestion among monomers within growing nanostructures. ${ }^{57,58}$ As a consequence, the energy diagram of anti-cooperative assembly exhibits fast nucleation followed by a relatively slow elongation 

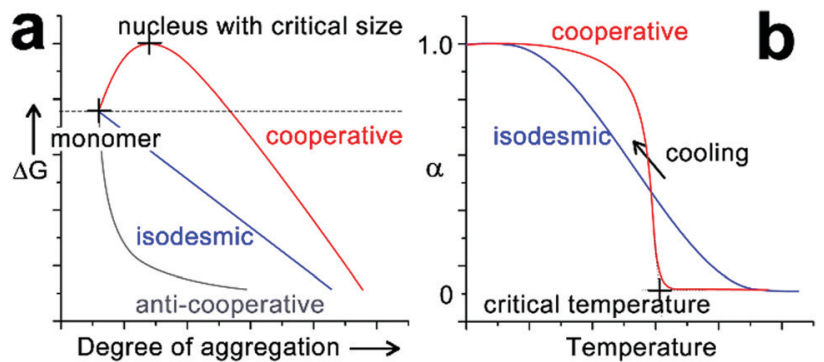

Fig. 2 (a) Qualitative energy diagram of cooperative (red), isodesmic (blue) and anti-cooperative (grey) assembly systems, as a function of the degree of aggregation. (b) Description of cooperative and isodesmic assemblies, defined by the fraction of aggregated species $(\alpha)$ upon cooling down from their monomeric hot solutions.

(Fig. 2a). In contrast, the cooperative assembly shows a decelerated nucleation until the formation of a nucleus with the critical size capable of initiating rapid elongation (Fig. 2a). This energetically unfavourable nucleation phase is commonly encountered in self-assembly processes driven by a combination of multiple non-covalent interactions, ${ }^{30,41,59,60}$ as such systems need the synergism of these non-covalent interactions, enhanced by growing degree of aggregation, to countervail adverse kinetic factors at an initial stage. The cooperative process is frequently encountered in self-assembly and applies to many cases involving amphiphilic peptides or peptide derivatives,${ }^{61-71}$ largely because these amphiphilic building blocks possess both hydrophilic and hydrophobic moieties responsible for monomer association through various non-covalent interactions.

The kinetically suppressed nucleation of cooperative assembly can be identified by the emergence of a thermal hysteresis between the heating- and cooling-cycle during variable temperature spectral studies. ${ }^{32,59,72-74}$ For most synthetic monomers following the cooperative mechanism, their supramolecular polymerizations are enthalpy-driven processes and thus occur upon cooling. ${ }^{34}$ Assuming there is no kinetic barrier on the assembly route, heating-aggregated structures and cooling molecularly dissolved monomers at a constant rate should generate the identical temperature-dependent curve. However, the heating and cooling curves of a cooperative system usually fail to overlap each other, as only the heat-induced disassembly normally proceeds under thermodynamic control. As a result, the fraction of aggregated species on the cooling curve corresponding to a specific temperature is smaller than that on the heating curve. Such hysteresis between temperature-dependent curves indicates that opposing reactions fail to equilibrate, due to the existence of a kinetic barrier for the monomer association in the initial stages of cooperative growth. ${ }^{59}$ As the nucleationelongation model of cooperative assembly is coupled with a kinetically suppressed initial nucleation, the monomer association to long aggregates is energetically preferred over the monomer self-nucleation. Given the energetically preferred elongation phase, equilibrium aggregates under the thermodynamic control are fragmented through sonication or mechanical agitation, and the resulting structures, relatively longer than the critical nucleus, can serve as seeds to enchain monomers in the cooperative growth. By avoiding the formation of high energy nucleus and pre-nucleus oligomers, this seeding method can divert the cooperative association to the elongation phase directly, thus speeding up the monomer conversion toward the final equilibrium structure. .0,74-76 $^{-10}$

\subsection{Cooperativity among multiple non-covalent interactions and associated pathway complexity}

The cooperative monomer association arises from the cooperativity of noncovalent interactions, including polarization, electrostatic, and hydrophobic effects, that are dictated by the short- and longrange organization of monomers. ${ }^{30}$ For example, the isodesmic assembly of perylene-bisimide (PBI) derivative PBI-C1 (Fig. 3a) in methylcyclohexane (MCH) was purely driven by the $\pi-\pi$ stacking of PBI cores, ${ }^{77,78}$ and its degree of aggregation derived from temperature-/concentration-dependent measurements displayed sigmoidal curves which are indicative of the isodesmic mechanism (Fig. 3b). ${ }^{30,32}$ In contrast, the PBI cores of PBI-C2, PBI-C3, and PBIC5 were tethered with amide substituents, thus resulting in folded molecular conformations through intramolecular hydrogen bonds (Fig. 3a and b). This H-bonding induced conformational restriction sequestered the planar PBI cores of PBI-C2, C3, and C5 from $\pi-\pi$ stacking, and the synergistic effect of intramolecular hydrogen bonds and $\pi-\pi$ stacking interactions resulted in the cooperative assembly. ${ }^{41,59,60,79}$ Folded PBI-C2, C3, and C5 monomers need to break their intramolecular hydrogen bonds to re-expose their aromatic cores for $\pi-\pi$ stacking. Accordingly, this energetically unfavored conformational change resulted in the slow nucleation of the cooperative assembly. As nucleation proceeded, however, extended monomers upon assembly formed multiple hydrogen bonds with neighboring units, which promoted a higher order of
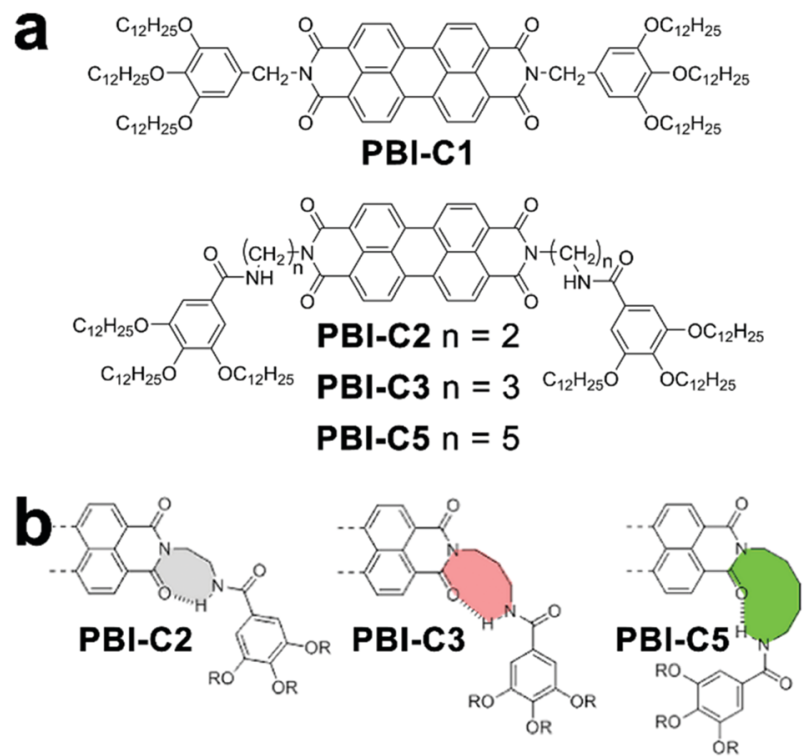

Fig. 3 (a) Chemical structures of $\mathrm{PBI}$ derivatives following isodesmic (PBI-C1) or cooperative (PBI-C2, C3, and C5) assembly mechanisms. (b) Proposed conformation of folded $\mathrm{PBI}-\mathrm{C} 2, \mathrm{C} 3$, and $\mathrm{C} 5$ due to intramolecular hydrogen bonds. Adapted with permission from ref. 60. Copyright 2016 American Chemical Society. 
$\pi-\pi$ stacking. ${ }^{80}$ With the formation of a critical nucleus, the enthalpic gain of monomer addition favored by multiple associations eventually offsetting the concomitant conformational penalty, which shifted the assembly of PBI-C2, C3, and C5 to the elongation regime.

In addition to the dictates on the assembly mechanism, the occurrence of cooperativity between assembling monomers may also exert influence on the assembly pathway. Synthetic monomers capable of multiple non-covalent interactions with cooperativity tend to generate kinetically preferred, nonequilibrium structures rather than the equilibrium structure under thermodynamic control. ${ }^{73,81}$ Due to the inherent lability of a non-equilibrium state, kinetic species always exhibit a conversion trend toward the thermodynamic equilibrium structure over time. However, activation barriers between kinetic and thermodynamic structures can significantly retard this spontaneous conversion, thus resulting in the pathway complexity of self-assembly. ${ }^{36}$ To overcome the activation barrier, external stimuli such as sonication, ${ }^{75}$ agitation, ${ }^{72}$ irradiation, and adding seeds ${ }^{74,76}$ have been applied on kinetic intermediates to achieve the thermodynamic structure situated in the global minimum of the energy landscape. It is noteworthy that the transformation from kinetic species to the thermodynamic structure can be distinguished in two situations: the consecutive pathway and the competitive pathway (Fig. 4). ${ }^{36}$ Along the consecutive pathway, non-equilibrium, kinetically trapped species directly build the equilibrium thermodynamic structure by reorganizing initial assemblies into higher-ordered architectures. ${ }^{38}$ Such kinetic species are on-pathway aggregates toward the final thermodynamic outcome (Fig. 4a). In contrast, kinetic species arising from the competitive pathway must disassemble into monomers before engaging in the thermodynamic state, and such kinetic intermediates are off-pathway aggregates with respect to the thermodynamic structure (Fig. 4b). Given building blocks conjugated with spectroscopic labels, the kinetic/thermodynamic transformation in the competitive pathway will be accompanied by the emergence of isosbestic points in UV-vis spectra and/or isodichroic points in CD spectra, indicating the transformation between structurally defined species. ${ }^{30,82}$

\subsection{Thermodynamic considerations on the assembly of amphiphilic peptides and peptide derivatives}

So far, our discussion on self-assembly has largely focused on the mechanistic aspects of synthetic monomers whose $\pi$-conjugated

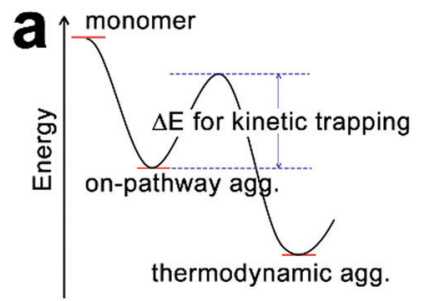

Consecutive pathway

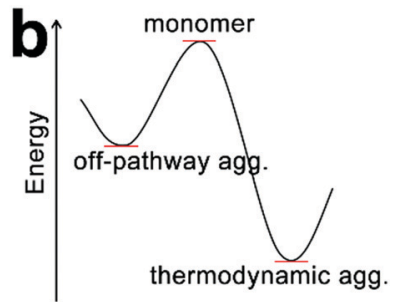

Competitive pathway
Fig. 4 Energy landscape of (a) consecutive and (b) competitive pathways. domains determine their enthalpy-driven association characterized by a ceiling temperature. ${ }^{24,35}$ Such cooling-motivated association originates from the enthalpic dispersion of synthetic monomers in apolar environments. Upon cooling, monomer associations driven by non-covalent bond formation are of an enthalpic nature and give off energy in the form of heat $(\Delta H<0)$. The enthalpic gain arising from non-covalent interactions countervail the entropic loss of associated monomers with reduced degrees of freedom, thus resulting in the enthalpically dominated assembly. In contrast to the enthalpic assembly of synthetic monomers, amphiphilic peptides and peptide derivatives often exhibit an entropy-driven aggregation in aqueous media, which is accompanied by a floor temperature. ${ }^{34}$ In aqueous environments, hydrophobic domains of peptidic amphiphiles cluster together to situate the charged and polar peptide segments toward water. Otherwise, the exposure of hydrophobic domains incapable of forming hydrogen bonds would force surrounding water molecules into highly directional arrangements, which results in significant entropy losses of the system. ${ }^{53-55}$ As peptide amphiphiles reveal a strong aggregation tendency to minimize the disruptive effect of nonpolar solute on reducing the mobility of water molecules, their assembly is principally driven by the entropic force. Given the entropic nature of amphiphile assembly, heating enhances the contribution of entropic gain $(\Delta S>0)$, therefore promoting the assembly of amphiphilic peptides and peptide conjugates. It is noteworthy that overheating peptidic assemblies breaks hydrogen bonds and destroys the hydration shell maintaining even dispersion, which leads to the precipitation of assembled structures. ${ }^{34}$

Our early thermodynamic interpretations on peptide self-assembly are largely derived from empirical observations on biomolecules in nature. ${ }^{83-88}$ Peptides in biological contexts go through spontaneous self-association to form secondary structures like $\alpha$-helices and $\beta$-sheets, which constitute the complex tertiary structure of proteins. ${ }^{8,89} \beta$-Sheets are of special importance among other secondary structures, as their presence often indicates the formation of amyloid fibers which closely correlate with protein misfolding diseases such as Alzheimer's disease.,23,90-92 Canonical $\beta$-sheet-forming peptides comprise alternatingly arranged hydrophobic and hydrophilic residues and these peptide segments undergo spontaneous association in water as stretched strands. ${ }^{93-95}$ Due to the directional constraints from hydrogen bonds along peptide backbones, multiple peptide strands are lined up next to each other to form the extended planar arrangement of peptide strands as $\beta$-sheets. Within these $\beta$-sheets, the orientation from $\mathrm{N}$ - to $\mathrm{C}$-terminus of adjacent peptide strands may adopt the same or opposite directions, thus offering parallel or antiparallel $\beta$-sheets, respectively. ${ }^{8,51}$ $\beta$-Sheet peptides have been recognized as the most effective programmable building blocks to construct nanostructures coupled with biocompatibility, biodegradability, as well as ease of large-scale synthesis. ${ }^{51}$ Previous studies brought reliable strategies to achieve spatial and temporal control over the morphology of peptidic assemblies. ${ }^{6,7,96,97}$ For example, Grover, Lynn and co-workers demonstrated that changing $\mathrm{pH}$ altered the strength of salt bridge between charged termini of $A \beta$ 
peptide Ac-KLVFFAE- $\mathrm{NH}_{2}$, the nucleating core of Alzheimer's disease, which produced peptide assemblies as nanofibers or nanotubes, respectively. ${ }^{7}$

Despite advances in modulating the assembly of peptides with natural design, the fundamental relationship between peptide sequence and corresponding assembly outcome remains elusive. ${ }^{98-100}$ To unambiguously determine essential motifs for peptide assembly, the systematic truncation and sequence modification on assembling peptides, assisted by well-established peptide synthetic approaches, become highly desirable. $^{23,51}$ Through a reductionist approach, Gazit and coworkers identified diphenylalanine (FF) as the minimal self-assembling motif of $\beta$-amyloid, evidenced by the formation of well-defined FF nanotubes upon diluting the monomeric hexafluoroisopropanol (HFIP) solution with water. ${ }^{101-106}$ Such initial studies on diphenylalanine-involved assembly demonstrate the crucial role of aromatic moieties in peptide/peptide derivative association. ${ }^{107-111}$ Meanwhile, based on simple and engineerable short peptide sequence, Ulijn and coworkers proposed more guiding principles for peptide assembly through computation and these principles can be experimentally verified as well. ${ }^{98,99,112-116}$ For instance, tripeptides containing two neighboring aromatic residues exhibit high assembly propensity and this propensity can be further enhanced when the $\mathrm{N}$ - and C-terminus of tripeptides are coupled with residues carrying complementary charges. ${ }^{99,117,118}$ In addition, nuances of peptide structure may cause the inversion of supramolecular chirality of peptide assemblies, despite the intrinsic chirality of amino acid residues. For instance, $\mathrm{pH}$, terminal charges, and the sequence of peptide isomers have been demonstrated to determine the eventual handedness of peptide superstructures. ${ }^{97,119-122}$

Amphiphilic peptides and peptide derivatives simultaneously contain hydrophilic and hydrophobic domains, both of which contribute toward the spontaneous monomer association synergistically. This synergism usually arises from the cooperativity among multiple non-covalent interactions, which suggests a cooperative mechanism, followed by the assembly of amphiphilic monomers. For instance, taking advantage of the monomer-buffering effect of kinetic intermediates, Hamachi et al. synthesized boronophenyl (BPmoc)-protected triphenylalanine peptide BPmoc- $\mathrm{F}_{3}$ capable of seeding-initiated fiber growth (Fig. 5). The growth of $B P m o c-F_{3}$ nanofiber followed the cooperative mechanism, as the temperaturedependent CD measurements on the fiber growth revealed a non-sigmoidal curve fitting well with cooperative model. Fully developed nanofibers at the thermodynamic state were fragmented by vortexing and sonication, and the resulting nanofiber segments were demonstrated to be seeds to provide active ends for the subsequent monomer association. As these seeds were fragmented from thermodynamic structures, the monomer addition on seeds avoided energetically disfavored self-nucleation of monomers. Therefore, the seeding assembly eliminated the energy barrier of kinetic-thermodynamic conversion and hence speeded up the nanofiber growth. ${ }^{68}$ Accordingly, the growing peptidic nanofibers stained by fluorescent probes were visualized using confocal laser scanning
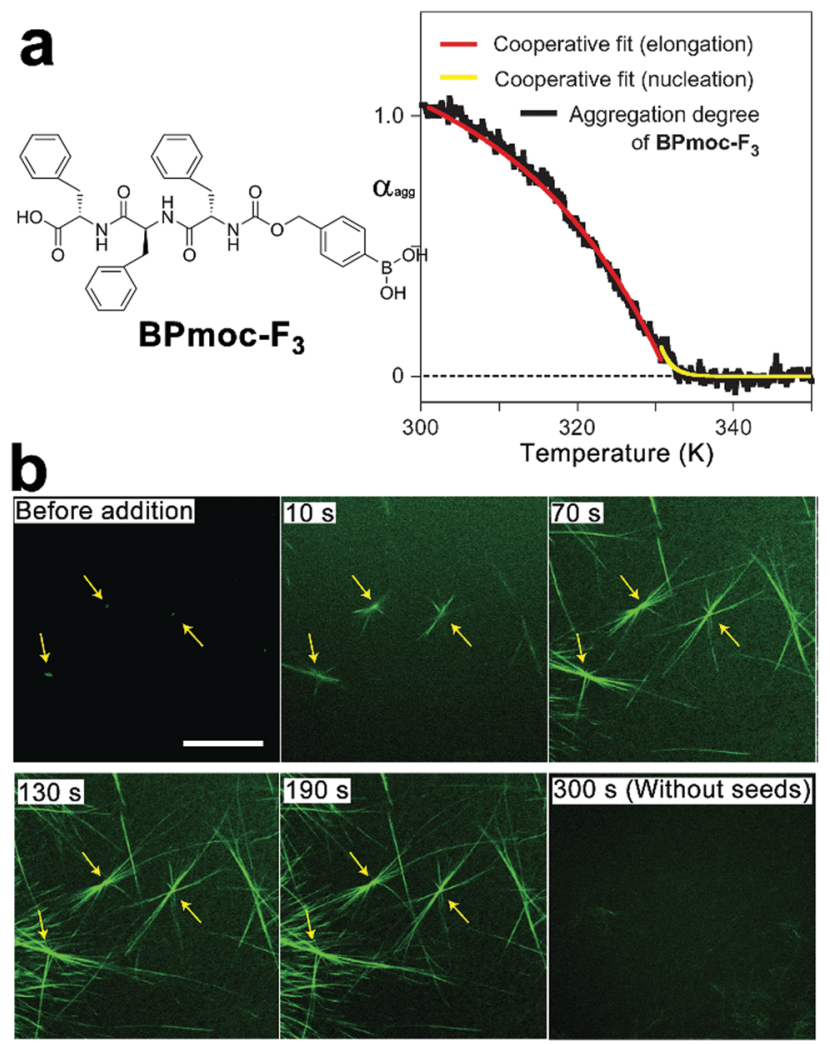

Fig. 5 (a) Molecular structure of BPmoc-protected triphenylalamine $\mathrm{BPmoc}-\mathrm{F}_{3}$ and its aggregation degree $\left(\alpha_{\text {agg }}\right)$ as a function of temperature, which was calculated from the temperature-dependent $C D$ measurements. (b) Time-lapse CLSM images showing the growth of BPmoc- $F_{3}$ nanofibrils after adding seeds for $0,10,70,130$, and $190 \mathrm{~s}$. As a comparison, the image at $300 \mathrm{~s}$ without adding seeds shows hardly any assembled structures. Adapted with permission from Macmillan Publishers Ltd: Nat. Chem., from ref. 68 , copyright 2016 .

microscopy (CLSM) and revealed a seeding-accelerated fiber growth as expected (Fig. 5b).

\section{Strategies to construct multicomponent nanostructures containing peptides/peptide derivatives}

\subsection{Programming functional chromophores into nanostructures by pre-linking with peptides}

There are twenty amino acids in nature, encoded by a gene, that makeup proteins across all living systems. ${ }^{83,84,123}$ According to the water affinity of their side chains, these natural amino acids can generally be divided into hydrophilic and hydrophobic. ${ }^{98}$ Hydrophilic amino acids usually carry polar or ionizable moieties, particularly, Asp, Glu, Lys, Arg, and His are electrically charged at physiological $\mathrm{pH}$, which renders them prevailing constituents in biomedical materials. ${ }^{124,125}$ Hydrophobic amino acids are featured by the presence of aromatic or aliphatic moieties and peptides consisting of aromatic 
residues, identified from $\beta$-amyloid, have been elucidated as important assembling motifs by extensive early studies. ${ }^{85,98,99}$

Through well-established methods of peptide synthesis, amino acid residues can be integrated into the peptide chain in a predetermined sequence. The programmability of peptide materials establishes their tunable properties, such as solubility, conductivity, and $\mathrm{pH} /$ thermal responsiveness, ${ }^{5,23,98}$ which make them versatile segments in tailoring the intrinsic properties of functional chromophores through peptide modification. ${ }^{126-128}$ For instance, $\pi$-conjugated chromophores are frequently used in organic optoelectronics, ${ }^{129-131}$ however, the poor water solubility due to aromatic structure hampers their usage in polar environments. ${ }^{5,132}$ Accordingly, these semiconductive aromatic chromophores are conjugated with hydrophilic peptides to ameliorate their solubility, as well to achieve peptide-assisted self-assembly. ${ }^{133-137}$ The aqueous self-assembly of resulting amphiphilic conjugates are largely determined by the hydrophobic effects of $\pi$-conjugated domains, as hydrogen bonding and permanent dipole-dipole interactions between hydrophilic peptide segments are attenuated in aqueous environments. ${ }^{98,99}$ However, with the presence of the electrically charged amino acid residues that produce strong electrostatic repulsion, the previously overwhelming attractive hydrophobic effects from $\pi$-conjugated chromophores can be significantly mitigated. ${ }^{5,134}$ As a consequence, the balance between hydrophobic effects and opposing electrostatic repulsion within assembling amphiphilic conjugates can be finely tuned, which enable the positioning of $\pi$-conjugated chromophores into well-defined nanoarchitectures. ${ }^{138,139}$

Despite the success in the self-assembly of D-A conjugates, the complex synthesis of desired peptidic monomers retards the progress of this strategy, which in turn motivates the exploration of the sorted co-assembly of simple peptidic building blocks. For example, Adams et al. demonstrated that by slowly decreasing the solvent $\mathrm{pH}$, the mixture of two naphthalene-functionalized dipeptide hydrogelators, NAPH-AV and NAPH-AA, coupled with different $\mathrm{p} K_{\mathrm{a}}$ achieved spatially resolved, self-sorted gelation networks (Fig. 6). ${ }^{140}$ This $\mathrm{pH}-$ triggered self-sorting emerged from the gradual acidification on the binary mixture that sequentially approached different $\mathrm{p} K_{\mathrm{a}}$ values of hydrogelators, thus triggering the gelation of corresponding components in sequence (Fig. $6 \mathrm{~b}$ and c). ${ }^{140}$ Following this sequential gelation strategy, D and A chromophores were, respectively, conjugated with various peptides to construct sorted nano-assemblies allowing efficient photoinduced charge separation. ${ }^{20}$ These studies highlight the great potential of kinetic factors, such as time, temperature, concentration, solvent composition, and mechanical agitation, on spatially engineering multiple components into one global complex integrated with sorted domains.

\subsection{Supramolecular block copolymers through hetero-seeding}

On a molecular level, monomers capable of co-assembly should possess geometrical resemblance on their structural motifs and display similar association behavior coupled with comparable free energy gains of homo-association, otherwise, they are likely

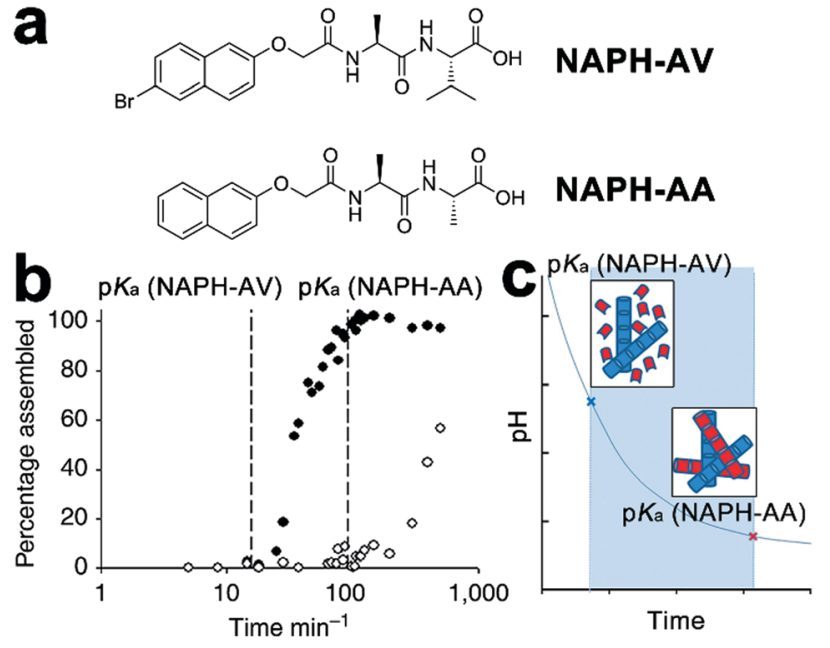

Fig. 6 (a) Chemical structures of dipeptide gelators NAPH-AV and NAPH-AA. (b) Degree of assembly derived from integration of NMR data, revealing the sequential gelation of NAPH-AV followed by NAPH-AA. (c) The decreasing $\mathrm{pH}$, due to the hydrolysis of glucono- $\delta$-lactone to gluconic acid, gradually approached the $\mathrm{p} K_{\mathrm{a}}$ of each component and triggered the assembly of NAPH-AV (blue building blocks) and NAPH-AA (red building blocks) in sequence. Adapted with permission from Macmillan Publishers Ltd: Nat. Commun., from ref. 140, copyright 2013.

to produce independently self-sorted homo-aggregates. ${ }^{29,141}$ Given co-assembly systems whose homo-association of respective monomers is energetically more favorable than hetero-association, the formation of the supramolecular block copolymer as heterogeneous nanostructures integrated with segments of homo-associated monomers may prevail. The construction of supramolecular block copolymer emerges from the development of living supramolecular polymerization. $^{72,73,81,142,143}$ As an early example, Sugiyasu, Takeuchi, and co-workers synthesized amides and tridodecylbenzene-bearing porphyrin derivatives capable of $\pi-$ $\pi$ interactions and intra-/intermolecular hydrogen bonding. ${ }^{72,81}$ These porphyrin derivatives were prone to form kinetically trapped, off-pathway J-aggregates over thermodynamically equilibrated $\mathrm{H}$-aggregates (Fig. 7), as assembling molecules prefer to form the kinetic intermediate with the lowest activation barrier regarding their predecessor, ${ }^{32,63}$ the monomeric porphyrin derivatives in this case. For the assumed consecutive pathway, increasing the concentration of starting monomers

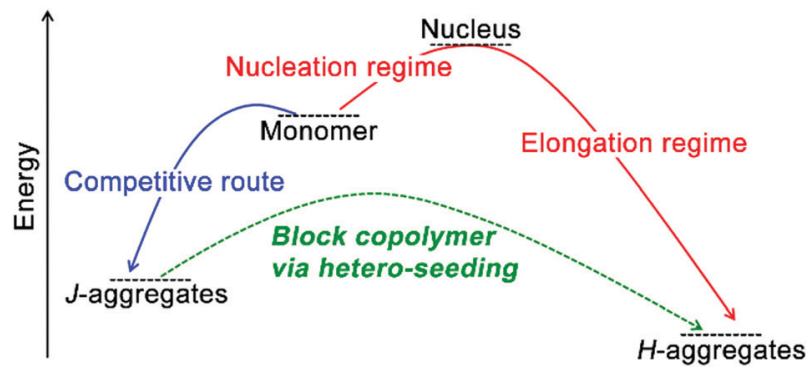

Fig. 7 Schematic illustration of the construction of supramolecular block copolymer through hetero-seeding strategy. 
should shift the assembly equilibrium toward its thermodynamic end, however, it failed to accelerate the formation of $\mathrm{H}$-aggregates here. Because J-aggregates of these porphyrin derivatives are off-pathway species with respect to thermodynamic $\mathrm{H}$-aggregates. Accordingly, larger monomer concentration encouraged the formation of J-aggregates, which entrapped monomers from engaging in the thermodynamic state. Therefore, increasing the monomer concentration enhanced the kinetic preference here on generating off-pathway structures, which in turn retarded the formation of thermodynamic aggregates. ${ }^{30,38}$ To stimulate the kinetic-thermodynamic transition, the authors added seeds, externally segmented from thermodynamic H-aggregates, to kinetically entrapped J-aggregates, which avoided the energetically suppressed reformation of monomers and nucleation and shifted the divergent assembly pathway to the swift elongation phase directly (Fig. 7). Moreover, this seeding strategy allows structural nuances of monomers, thus applicable to co-assembly systems. ${ }^{72,73,142}$ Therefore, sequentially feeding the living ends of growing seeds with nonself-monomers (heteroseeding) produces supramolecular block copolymers (Fig. 7).

Taking advantage of the hetero-seeding strategy, growing assemblies of amphiphilic peptide derivatives can be fed with nonself-monomers and these freshly added monomers may associate with preformed assemblies to produce heterogeneous block architectures. ${ }^{142,143}$ Otto, van der Gucht et al. studied the cooperative fiber growth of macrocyclic hexamers of $\mathrm{SH}-\mathrm{Ph}$ and SH-Cy and prepared triblock copolymers by treating the preformed hexamer seeds of SH-Cy with non-assembling trimers or tetramers of $\mathrm{SH}-\mathrm{Ph}$ (Fig. 8). ${ }^{66}$ The peptidedecorated dithiol monomers $\mathrm{SH}-\mathrm{Ph}$ and $\mathrm{SH}-\mathrm{Cy}$ in this study contained similar peptide segments for the $\beta$-sheet formation and used disulfide chemistry to construct the same hexametric core. As peptidic building blocks here possessed geometrical resemblance on their structural motifs, they were able to coassemble with each other through a hetero-seeding approach. When segmented hexamer nanofibers of $\mathrm{SH}-\mathrm{Cy}$ were treated with trimers and tetramers of $\mathrm{SH}-\mathrm{Ph}$, these non-assembling trimers and tetramers spontaneously rearranged to hexamers to associate with preformed nanofibers, thus generating triblock nanofibers. The formation of hexamer fibers started from the oxidation of peptide-functionalized dithiol-building blocks of $\mathrm{SH}-\mathrm{Ph}$ or $\mathrm{SH}-\mathrm{Cy}$ upon air exposure, which yielded macrocyclic disulfides as trimers and tetramers (Fig. 8b). While these metastable trimers and tetramers were incapable of forming nanofibers, applying mechanical agitation on them causing the dynamic exchange of reversible disulfide bonds and thus producing hexamers serving as the starting nuclei to initiate the following hexamer stacking (Fig. 8c). Moreover, continuous agitation caused fragmentation of growing fibers, which produced more active ends for hexamer stacking and resulted in the exponential elongation of hexamer nanofibers. ${ }^{66,67}$

\subsection{Peptide assemblies coated by polyelectrolytes}

Despite the desirable features of peptidic assemblies such as self-correcting, adaptable, and stimuli-responsive properties, their susceptibility toward environmental changes weakens
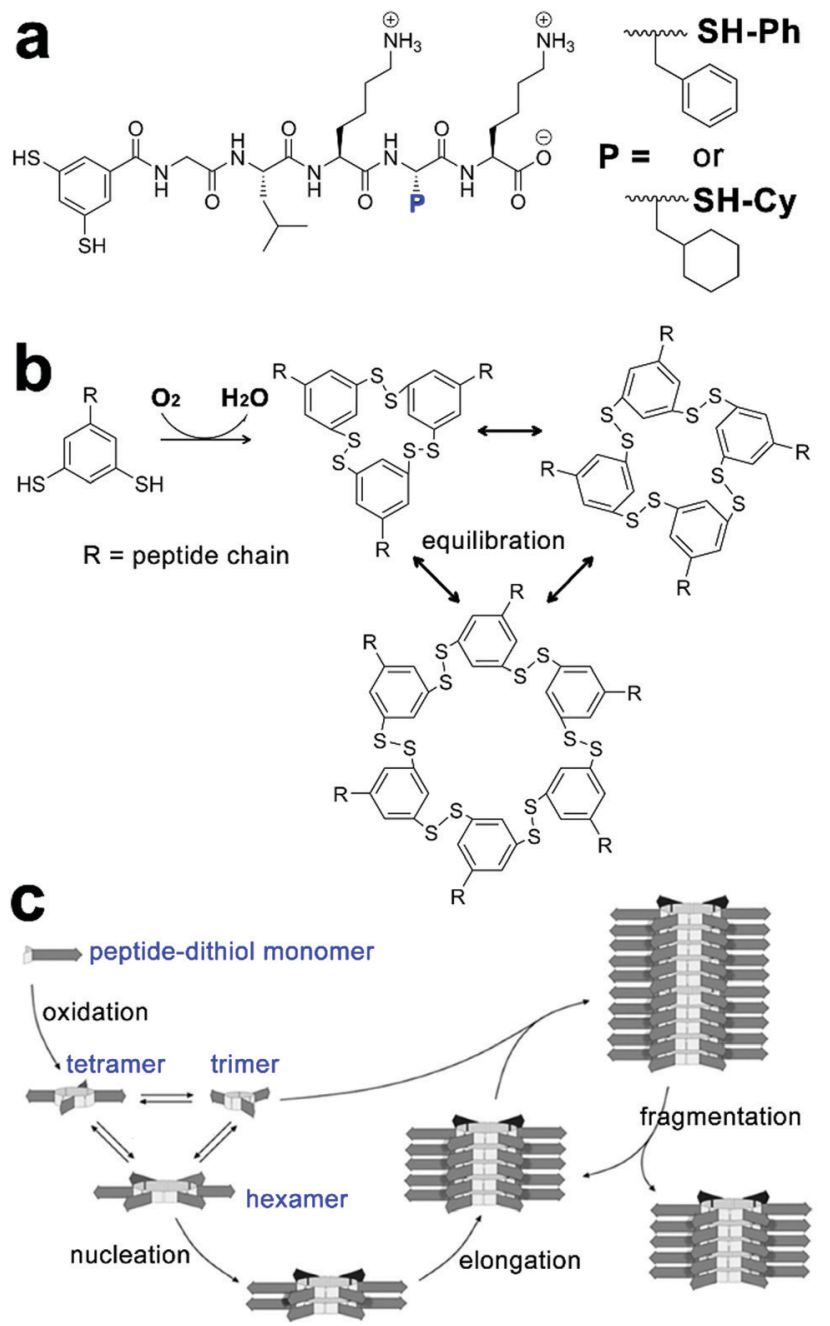

Fig. 8 (a) Molecular structures of peptide-functionalized dithiol monomers $\mathrm{SH}-\mathrm{Ph}$ and $\mathrm{SH}-\mathrm{Cy}$. (b) Oxidation-triggered cyclization of peptide-dithiol monomers yields a mixture of trimers, tetramers, and hexamers capable of constant disulfide exchange. (c) Hexamers of peptide-dithiol molecule assemble into nanofibers through the $\beta$-sheet formation of peptide segments (arrow parts). Upon mechanical agitation, the fragmentation of hexamer fibre generates more active ends for further elongation. Figure adapted with permission from ref. 66. Copyright 2015 Wiley-VCH.

their structural integrity against adverse environmental circumstances, which compromises their performance in practical utilizations. Stupp and coworkers synthesized a set of peptide amphiphiles (PA) by conjugating $\beta$-sheet forming peptides with hydrophobic tails and these PAs self-assembled into one-dimensional fiber-like nanostructures in aqueous environments. ${ }^{70}$ As long PA nanofibers were superior to shorter ones in supporting cell adhesion, the thermodynamic and kinetic factors regulating fiber growth were explored to preserve their longitudinal dimensions with bioactivity. ${ }^{70,144}$ For example, above the critical ionic strength $\left(I_{c}\right)$ of $6 \mathrm{mM}$, the alkyl $\left(\mathrm{C}_{16}\right)$ conjugated peptide sequence $\mathrm{V}_{3} \mathrm{~A}_{3} \mathrm{~K}_{3}$ spontaneously achieved its thermodynamic structure as ultralong nanofibers. ${ }^{70}$ Upon dilution, however, the ionic strength dropped down below $I_{\mathrm{c}}$, which largely removed the previous charge-screening effect on 
lysine residues of $\mathrm{V}_{3} \mathrm{~A}_{3} \mathrm{~K}_{3}$. As weakened charge screening effect, in turn, strengthened the charge repulsion on peptide sequence, the assembly of alkyl-conjugated $\mathrm{V}_{3} \mathrm{~A}_{3} \mathrm{~K}_{3}$ was attenuated, which converted the previous thermodynamic structures as ultralong fibers into kinetically trapped species. Accordingly, heating these kinetically trapped ultralong fibers upon dilution resulted in their dissociation and generated monodispersed short segments instead. ${ }^{70}$ Notably, the energy barrier of this ionic strengthinduced kinetic-thermodynamic transition was calculated as $171 \mathrm{~kJ} \mathrm{~mol}^{-1},{ }^{70}$ indicating high structural integrity capable of counteracting competitive effects as strong as electrostatic interactions or hydrogen bonds. Therefore, well-defined, peptidebased nano-assemblies may serve as stable frameworks allowing the sequential positioning of distinct components through multiple non-covalent interactions.

To improve the structural integrity of peptidic assemblies, Parquette and co-workers created conformal polydopamine (PDA) coating around self-assembled nanofibers of naphthalenediimide-dilysine NDI-KK, which rendered the resulting nanofibers impervious toward adverse changes in $\mathrm{pH}$ and temperature (Fig. 9). ${ }^{145}$ The self-assembly of NDI-KK in water, driven by the $\beta$-sheet formation of dilysine and J-type $\pi-\pi$ stacking of NDI, generated 1D helically twisted nanofibrils (Fig. 9a). ${ }^{134}$ Also, the self-assembly of NDI-KK was carried out at $\mathrm{pH} 8.0$ to attenuate the unfavorable electrostatic repulsion for fiber growth due to the protonation of lysine residues. After $12 \mathrm{~h}$ of incubation, the resulting nanofibers were treated with dopamine, a common hormone capable of oxidative selfpolymerization in alkaline solutions, to produce a crosslinked PDA coating around them, ${ }^{146,147}$ thus generating the PDA/NDI-KK composite. The starting NDI-KK nanofibers were susceptible to external stimuli and dissociated after heating or under acid conditions, in contrast, the PDA/NDI-KK composite with the protective, conformal PDA coating exhibited muchstrengthened resilience toward adverse environmental factors. As demonstrated by circular dichroic (CD) spectra and dynamic light scattering (DLS) measurements, the chiral stacking of NDI chromophores within PDA/NDI-KK withstood acid $\mathrm{pH}$ as low as 3.0 and the overall dimension of PDA/NDI-KK remained stable from $25-70{ }^{\circ} \mathrm{C}$ (Fig. 9b)..$^{145}$

\subsection{Entrapping carbon nanotubes with amphiphilic peptide derivatives}

Single-walled carbon nanotubes (SWNTs) are expected as ideal candidates for optoelectronic applications due to their unique electronic properties emerging from continuous 1D structures. ${ }^{148}$ However, SWNTs exhibit strong insolubility in polar environments, which causes detrimental bundling of SWNTs and restricts their processability in device fabrication. Early studies demonstrate surfactants and synthetic lipids can form stable and organized coating layers on the surface of SWNTs, ${ }^{149}$ through a spontaneous process modulated by the interplay between repulsive electrostatic interactions and attractive van der Waals force. ${ }^{150}$ With the presence of aromatic residues capable of hydrophobic interaction with SWNTs, amphiphilic peptides and peptide derivatives are also
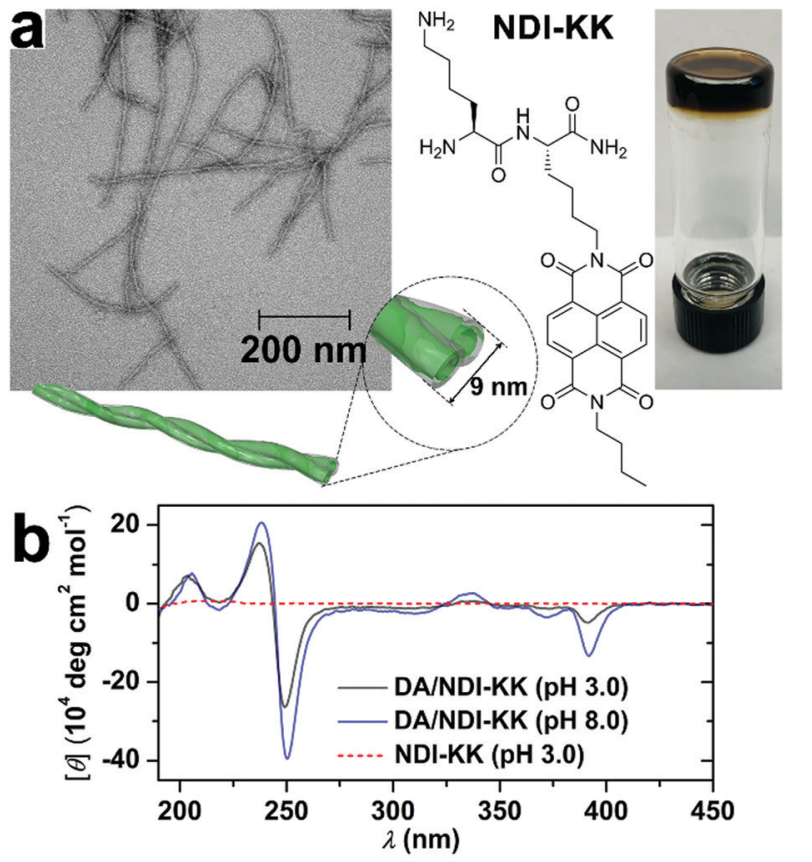

Fig. 9 (a) TEM image of PDA/NDI-KK nanofibers and the chemical structure of peptide amphiphile NDI-KK. On the right panel, the photo of PDA/NDI-KK hydrogel after incubation at $\mathrm{pH} 8.0$ for $24 \mathrm{~h}$. (b) $\mathrm{CD}$ spectra of PDA/NDI-KK composites at $\mathrm{pH} 3.0$ and 8.0 in water. As a comparison, NDI-KK at pH 3.0 showed no CD signature. Reproduced with permission from ref. 145. Copyright 2020 Wiley-VCH.

employed to exfoliate and stabilize SWNTs under aqueous conditions. ${ }^{151,152}$ In addition, thiol-containing peptides capable of reversible cyclization around SWNTs ${ }^{153,154}$ and cyclic peptides appended with pyrene moieties ${ }^{155}$ have been used to functionalize SWNTs and achieve their aqueous solubilization as well. Recently, Thomas, Kruss and coworkers demonstrated that a coiled-coil peptide rendered SWNTs water-soluble by forming heptamer peptide barrels to encapsulate SWNTs. ${ }^{156}$ This coiled-coil peptide, by itself, formed peptide barrels with channel cavities accessible to hydrophobic molecules. ${ }^{157}$ Upon mixing with SWNTs, the coiled-coil peptide barrels by heptamer generated a channel with a pore dimension compatible with the diameter of typical SWNT species. Therefore, multiple peptide barrels encapsulated SWNTs and produced a coaxial peptide coating layer along the length of SWNTs. ${ }^{156}$ This strategy can tailor the surface of SWNTs via non-destructive modification, thus preserving the optical properties of SWNTs. Moreover, coiled-coil peptides can form well-defined tubular structures with tunable diameters, which envisage their potential in discriminating SWNTs according to the dimension.

Parquette and co-workers encapsulated single-walled carbon nanotubes (SWNTs) with self-assembled nanotubes of naphthalenetetracarboxylic acid diimide-lysine bolaamphiphile, NDI-bola (Fig. 10). ${ }^{158}$ The preformed NDI-bola nanotubes were segmented by sonication prior to mixing with SWNTs to reduce potential steric congestion upon entrapping carbon nanotubes. The resulting nanotube segments encapsulated SWNTs via electrostatic and cation- $\pi$ interactions, meanwhile, 
a

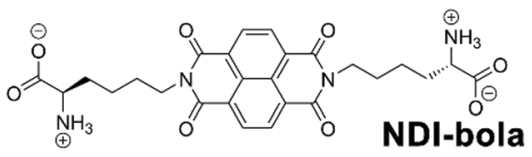

NDI-bola nanotube

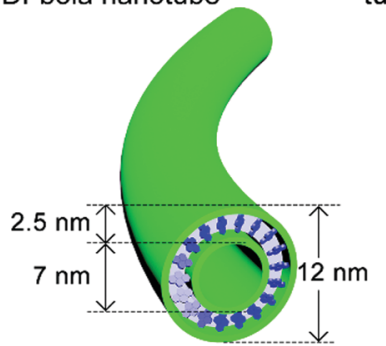

tubular hybrid SWNT/NDI-bola
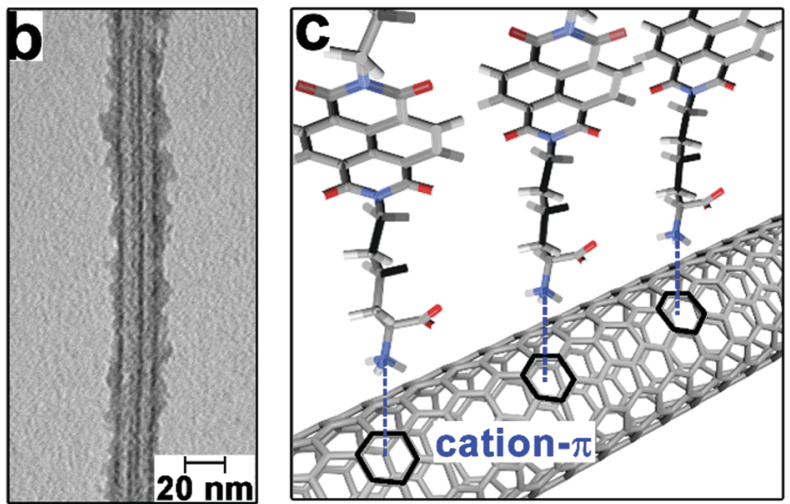

Fig. 10 (a) Chemical structure of the bolaamphiphile NDI-bola, schematic graphics of NDI-bola nanotube and the co-axial tubular nanohybrid of SWNT/NDI-bola. (b) TEM image of the co-axial SWNT/NDI-bola nanohybrid. (c) Schematic presentation of the electrostatic and cation $-\pi$ interactions between the inner channels of NDI-bola nanotubes and SWNTs after sonication-assisted progressive encapsulation. Adapted from ref. 158 with permission from the Royal Society of Chemistry.

the inherent thermodynamic propensity of supramolecular structures on self-healing ${ }^{159-161}$ re-combined nanotube segments along the length of SWNTs to form the continuous coaxial coating (Fig. 10b and c). ${ }^{162}$ Notably, the encapsulation of SWNTs by NDI-bola nanotubes resulted in the overlap of their electrical double layers (EDL), which reduced the surface charge of the outermost layer of lysine residues and redistributed monomeric bola amphiphiles from solvent to aggregates according to the colloidal particle theory. ${ }^{163,164}$ To mitigate the compromised dispersibility due to reduced surface charge, monomeric NDI-bola formerly dispersed in solvent engaged in the formation of the bilayer wall of SWNT/NDI-bola hybrids. In addition, the surface of SWNT/NDI-bola hybrids were wrapped by various conjugated polyelectrolytes through electrostatic interactions ${ }^{165}$ to achieve three-component, coaxial tubular nanohybrids for potential optoelectronic applications.

\subsection{Welding heterogeneous tubular segments}

Non-specific interactions with few directional constraints, such as the electrostatic interaction, may also assemble heterogeneous subunits into hierarchical composites with nanoscale precision. Kameta and co-workers synthesized two undecyl lipids Phe- $\mathrm{C}_{11}$-Gly-COOH and Phe- $\mathrm{C}_{11}-\mathrm{Gly}^{-} \mathrm{NH}_{2}$ that, respectively, assembled into nanotubes with matched diameters and wall thicknesses in water ${ }^{46}$ Both lipids carried an uncharged terminus of phenylalanine derivatives that constituted the neutral exterior of resulting lipid nanotubes; the carboxyl glycine head of $\mathrm{Phe}^{-\mathrm{C}_{11^{-}}}$ Gly- $\mathrm{COOH}$ and the amino glycine head of Phe- $\mathrm{C}_{11}-\mathrm{Gly}^{-} \mathrm{NH}_{2}$ made up the negatively and positively charged nanotube interiors, respectively (Fig. 11). These oppositely charged interiors arose attractive electrostatic interactions over cross-sections of these two nanotubes, which combined these tubular segments at open ends (Fig. 11a). ${ }^{46}$ After the electrostatic combination, tubular segments with oppositely charged interiors adopted an alternating arrangement to create heterogeneous nanotubes with blocked inner channels where amine and carboxylic sections were alternately distributed. When a pH-responsive fluorophore CypHer5 with a $\mathrm{p} K_{\mathrm{a}}$ of 6.1 traversed these blocked nanochannels, the ionization of amine/carboxylic interiors caused the deprotonation/protonation of CypHer5 and thus resulting in its intermittent fluorescence emission. ${ }^{46}$

\subsection{Peptide assembly directed by complementary base pairing}

Synthetic oligonucleotides can achieve stoichiometric complexation through complementary base pairing. As supramolecular templates, single-strand oligonucleotides successfully modulated the fine positioning of functional chromophores capable of complementary base pairing with nucleotidic templates to form uniform nanohybrids. ${ }^{166,167}$ Chau and Ni synthesized a series of tri-segmented peptides which were constituted by an N-terminal oligocation for DNA binding, a middle amyloid-derived segment for $\beta$-sheet formation, and a C-terminal hydrophilic segment for water solubility. In aqueous environments, DNAs entrapped by cationic segments were segregated from environmental surroundings by laminated $\beta$-sheet layers to form viral capsid-like nanofibrils/ nanoribbons. The resulting capsid-like structures are then converted into higher-ordered assemblies through lateral association, which can be useful in constructing gene delivery vehicles. ${ }^{168-170}$

Taking advantage of the reversible Watson-Crick base pairing, Stupp and coworkers studied the reversible intertwining and bundling of alkylated peptide nanofibrils with a surface distribution of complementary oligonucleotides (Fig. 12). ${ }^{171}$ In water, peptide amphiphile (PA) of alkyl $\left(\mathrm{C}_{16}\right)$-conjugated $\mathrm{V}_{3} \mathrm{~A}_{3} \mathrm{E}_{3}$ self-assembled into nanofibers by projecting their peripheral hydrophilic $\beta$-sheet segments from their hydrophobically collapsed alkyl cores. Based on this self-assembling PA precursor, complementary oligonucleotides were covalently attached on PA, respectively, thus yielding complementary conjugates PA-DNA-1 and PA-DNA-1' ${ }^{\prime}$ (Fig. 12a). As PA co-assembled with PA-DNA-1 or PA-DNA-1' ${ }^{\prime}$ in molar percentages from $0.1 \%$ to $10 \%$, the resulting PA/PA-DNA- 1 and PA/PA-DNA-1' ${ }^{\prime}$ nanofibrils were randomly distributed with complementary oligonucleotide sequences on their surfaces. Due to the DNA hybridization between PA/PA-DNA-1 and PA/PADNA-1' $1^{\prime}$ fibers, their aqueous dispersions produced gelation after mixing, which generated a nanofibrous network embedded with micrometer-sized bundles of intertwined filaments (Fig. 12b and c). ${ }^{171}$ Confocal optical microscopy revealed DNA-containing PA-DNA-1 and PA-DNA- ${ }^{\prime}$, labeled with a fluorescent dye Cy3, were 
a<smiles>CCC(=O)NC(Cc1ccccc1)C(=O)NI(C)NC(=O)NCC(=O)NCC(=O)O</smiles>

Phe-C 11 -Gly-COOH<smiles>CCNC(=O)C(Cc1ccccc1)NC(=O)NCC(=O)NCC(=O)CN</smiles>

Phe $-\mathrm{C}_{11}-$ Gly- $\mathrm{NH}_{2}$

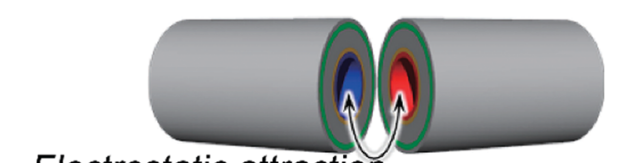

Electrostatic attraction

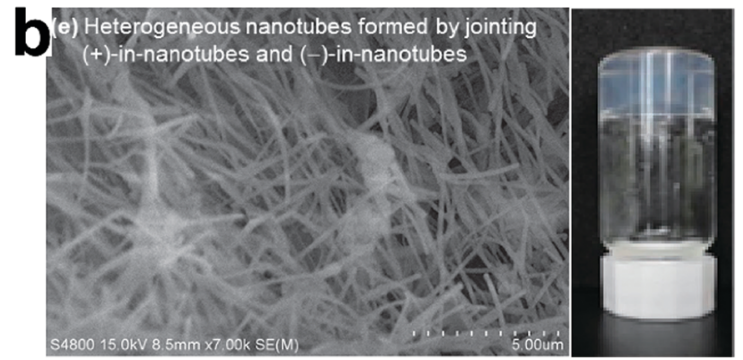

Fig. 11 (a) Chemical structures of undecyl lipids Phe- $\mathrm{C}_{11}-\mathrm{Gly}-\mathrm{COOH}$ and Phe- $\mathrm{C}_{11}-\mathrm{Gly}-\mathrm{NH}_{2}$, and their nanotubes with oppositely charged interiors which can be combined at open ends. (b) Scanning electron micrograph (SEM) image of heterogeneous nanotubes after mixing dispersions of Phe- $\mathrm{C}_{11}-\mathrm{Gly}-\mathrm{COOH}$ and Phe- $\mathrm{C}_{11}-\mathrm{Gly}-\mathrm{NH}_{2}$, and the photograph of the resulting hydrogel. Adapted from ref. 46 with permission from the Chemistry Society of Japan.

enriched in twisted bundles. Considering PA-DNA-1 and PADNA-1' were evenly distributed in the starting PA/PA-DNA-1 and PA/PA-DNA-1' nanofibers, the author reasoned that the formation of DNA-rich bundles was due to the redistribution of DNA-attached monomers within and among neighboring fibers. To demonstrate how the electrostatic interactions between nucleotides affected the growth of the superstructure, nucleotide sequences in PA-DNA-1 and PA-DNA-1 ${ }^{\prime}$ were replaced by shorter counterparts to attenuate their charge repulsion. Moreover, one of the short nucleotide sequences was converted to peptide nucleic acid (PNA) sequence to completely remove the charged phosphate-sugar backbone, thus generating PA-PNA conjugate PA-PNA-2 and PA-DNA conjugate PA-DNA-2' (Fig. 12a). PA-PNA-2 assembled into well-defined nanofibers, in contrast, the overwhelming charge repulsion of PA-DNA-1, PA-DNA- $1^{\prime}$ and PA-DNA-2 ${ }^{\prime}$ precluded the formation of any higher-order nanostructures on their own but simple spherical aggregates. Finally, the hybridization between complementary PNA and DNA sequences produced intertwined PA-PNA-2/PA-DNA-2' nanofibers with regular pitches, and further hybridization among these intertwined fibers produced twisted bundles over time (Fig. $12 \mathrm{~d}$ and e). ${ }^{171}$

\subsection{Nanostructures constituted by cyclic peptides}

Studies on cyclic peptides propose well-defined peptidic building blocks to the construction of tubular nanostructures.
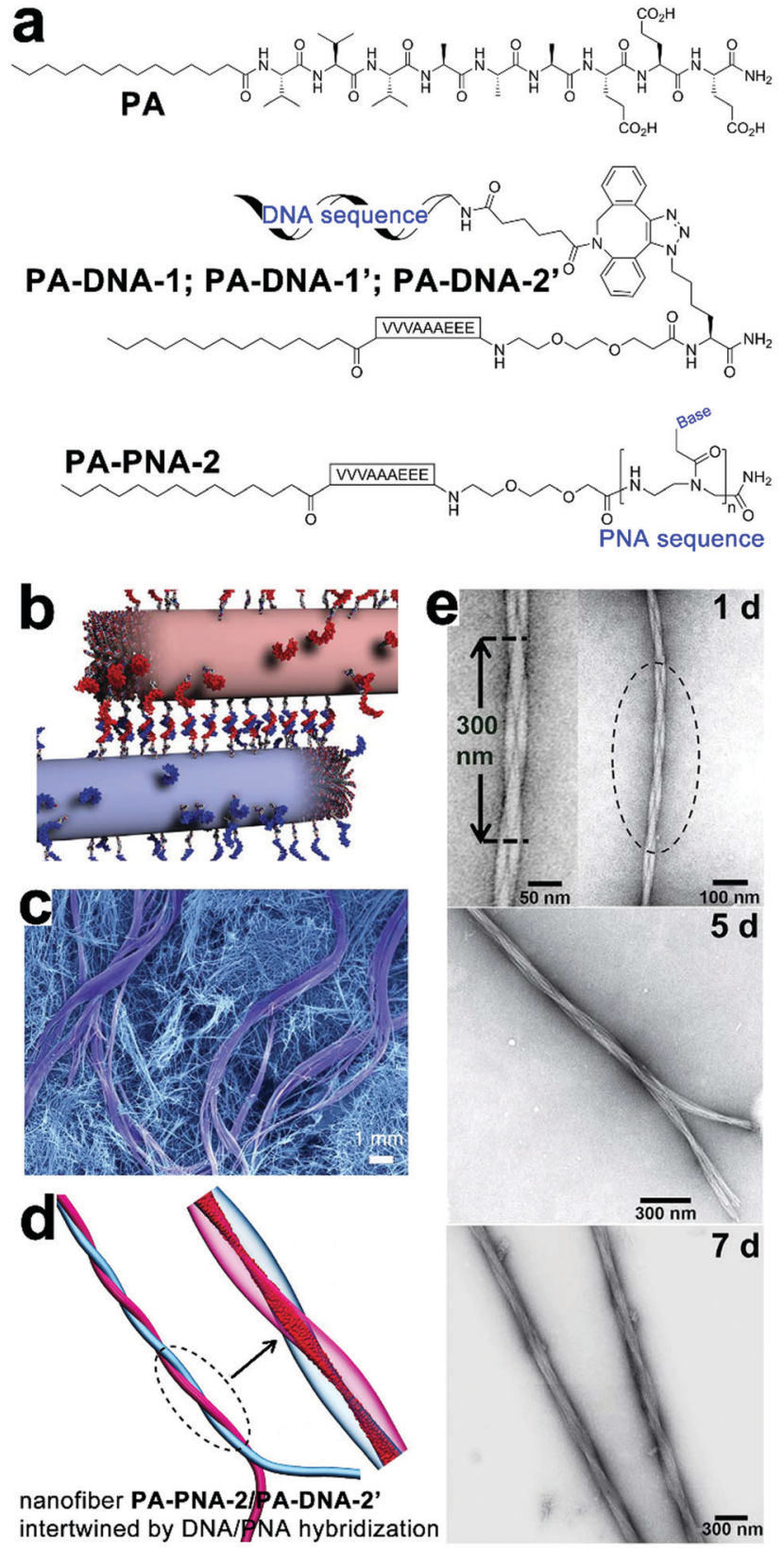

Fig. 12 (a) Chemical structures of peptide amphiphile (PA) of alkyl $\left(C_{16}\right)$ conjugated $\mathrm{V}_{3} \mathrm{~A}_{3} \mathrm{E}_{3}$, complementary pairs of conjugates PA-DNA-1/PADNA-1' ${ }^{\prime}$ and PA-PNA-2/PA-DNA-2'. (b) PA/PA-DNA-1 and PA/PA-DNA-1' nanofibers combined by DNA hybridization. (c) SEM image reveals bundles of intertwined filaments within the gelation network of individual nanofibers. (d) Simulation snapshot of intertwined PA-PNA-2/PA-DNA-2' nanofibers. (e) TEM images of intertwined PA-PNA-2/PA-PNA-2' nanofibers evolved into twisted bundles over time. Adapted from ref. 171 with permission from AAAS.

Early studies by Granja, Ghadiri and co-workers showed that hollow tubular nanostructures could be achieved from the extended ring-stacking of cyclic polypeptides. ${ }^{172-175}$ For instance, a cyclic octapeptide consisting of alternating D- and L-amino acid residues adopted a free-energy-optimized flat conformation to situate its backbone amides perpendicularly with respect to the cyclic plane. With the protonation of glutamic 
acid residues, multiple cyclic peptides stacked with each other via $\beta$-sheet-like intermolecular hydrogen bonding, therefore producing hundreds nm long tubular structures with internal diameters of 7-8 $\AA^{172}$

Smaller peptide rings, as simple as cyclic dipeptides were demonstrated, by Govindaraju et al., to form various nanoarchitectures, including nanotubes, nanospheres, and nanosheets through tailoring the length of alkyl appendants on dipeptide rings. ${ }^{176,177}$ The geometry of cyclic dipeptides enables them to project their appended side groups toward the peripheral. Accordingly, the self-assembly of cyclic dipeptides tethered with fluorescent chromophores regulated these chromophores into restricted stacking, which produced strong aggregation-induced emission (AIE). ${ }^{178}$ Moreover, with the presence of butyloxycarbonyl ( $t$ Boc) group capable of hostguest interaction with $\beta$-cyclodextrin $(\beta-\mathrm{CD})$, the self-assembly of $t$ Boc-cyclo-dipeptide was regulated by the addition of a competing guest molecule, adamantane carboxylic acid. ${ }^{179}$

Recently, Perrier and co-workers demonstrated that polymers conjugated with cyclic peptides allowed further modification/ complexation, which generated the tubular nanostructure owing to functional polymeric corona. ${ }^{180-182}$ For instance, through reversible addition-fragmentation chain transfer (RAFT), the block copolymer poly(acrylic acid)-polyisoprene was grafted onto a cyclic octapeptide. ${ }^{183}$ Along with the stacking of cyclic peptide cores, this block copolymer-cyclic peptide conjugates assembled into tubular structures consisting of multiple polymer shells. Moreover, through the selective crosslinking of the outer acrylic acid shell and ozonolysis removal of the inner polyisoprene shell, the previous tubular assemblies could be converted into nanotubes with tunable dimensions of the inner core. ${ }^{183}$ The presence of polymer side chains can also provide extra control on the extent of cyclic peptide stacking. ${ }^{184}$ For instance, cyclic peptides were conjugated with pH-responsive poly (dimethylamino ethyl methacrylate) (pDMAEMA) to produce cylindrical polymer brushes under basic conditions. ${ }^{184}$ However, reducing environmental $\mathrm{pH}$ enhanced the protonation of pDMAEMA arms, which gave rise to stronger electrostatic repulsion between cyclic peptide-pDMAEMA conjugates, thus attenuating their propensity on aggregation. ${ }^{184}$ In addition, the cyclic peptide core could be appended with hydrophobic or guest groups, thus providing extra stabilization ${ }^{185}$ or embedding the host-guest switch ${ }^{186}$ to the assembly of cyclic peptide-polymer conjugates, respectively.

\section{Functioning of peptide/peptide derivative-containing nanocomposites modulated by the spatial organization}

\subsection{Positioning silver nanoparticles into ordered arrays}

Controllable nucleation of heavy metals establishes the preparation of functional metallic nanoparticles applicable to tunable plasmonic resonance, catalysis, antimicrobial, etc. However, metal nanoparticles, with high surface energy, usually exhibit a strong propensity for aggregation, which severely compromise their intrinsic properties. ${ }^{187}$ Given amino acid residues accessible for further functionalization, peptide derivates carrying nucleation/binding sites are employed to construct well-defined biotemplates for the preparation of stably dispersed metal nanoparticles. Liu and coworkers synthesized a fluorenylmethoxycarbonyl (Fmoc)-peptide amphiphile, which assembled into fibrous structures. ${ }^{10}$ The surface of the resulting nanofibers was distributed with carboxylic acid and thiol groups. Upon reduction by sodium borohydride, silver ions adsorbed by carboxylic moieties nucleated into silver nanoparticles (AgNPs) and these AgNPs were further stabilized by thiol groups through the formation of coordinate covalent bonds. ${ }^{10}$ Stupp and co-workers developed an aldehydeattached peptide-amphiphile capable of forming high-aspectratio nanofibers with a complete surface coverage by aldehyde moieties. $^{188}$ As one aldehyde moiety can stoichiometrically reduce two silver ions to $\mathrm{Ag}_{2}$ cluster via the Tollens' reaction, ${ }^{189}$ the aldehyde surface of resulting nanofibers enabled the site-specific nucleation of silver ions along the longitudinal axis, which produced metallic peptide nanofibers exhibiting antimicrobial effect and less toxicity toward eukaryotic cells. ${ }^{188}$

Despite the stable dispersion of AgNPs along with peptide frameworks, the spatial arrangement of nanoparticles largely remains poorly ordered. Employing phenylalanine-based amphipathic self-assemblies of enantiomeric L-NAPH-Phe and D-NAPH-Phe as chiral templates, Srivastava $\boldsymbol{e t}$ al. successfully prepared helical tapes of polydopamine (PDA) to position AgNPs into the specific chiral arrangement. (Fig. 13). ${ }^{190}$ In sodium bicarbonate solution ( $\mathrm{pH}$ 10), L-NAPH-Phe and D-NAPH-Phe with primary amine residues spontaneously assembled into $(P)$ - and $(M)$-helical tapes, respectively. Polymerized dopamine contains electrophilic catechol quinones, which create its inherent reactivity toward the nucleophilic amines. ${ }^{191}$ Therefore, treating amine-contained L-NAPH-Phe and D-NAPH-Phe helical tapes with dopamine resulted in the formation of covalent PDA coatings over helical tapes via the in situ, oxidative self-polymerization of dopamine in alkaline solutions (Fig. 13a). Presumably, due to the $\mathrm{pH}$-dictated ionization of catechol residues, PDA-coated helical tapes, which completely rolled up into nanotubes at $\mathrm{pH} 7$ were re-opened into loose helices as $\mathrm{pH}$ increased from 7 to 10 (Fig. 13b). Moreover, the polyphenolic PDA served as mild reducing agents ${ }^{192}$ for AgNP nucleation and the resulting AgNPs were preferentially positioned along the edge of PDA-coated helical tapes, thus integrating AgNPs into supramolecular architectures with predefined chirality (Fig. 13c).

\subsection{Immobilizing multiple functional proteins on peptidic assemblies}

The functional competence of synthetic proteinaceous materials highly hinges on the integration of multiple proteins into hierarchical architectures in optimized combinations, as well as in well-defined ratios. Collier and coworkers prepared fluorescent composites by incorporating multiple fluorescent proteins with $\beta$-sheet fibrils, and the color of the resulting 

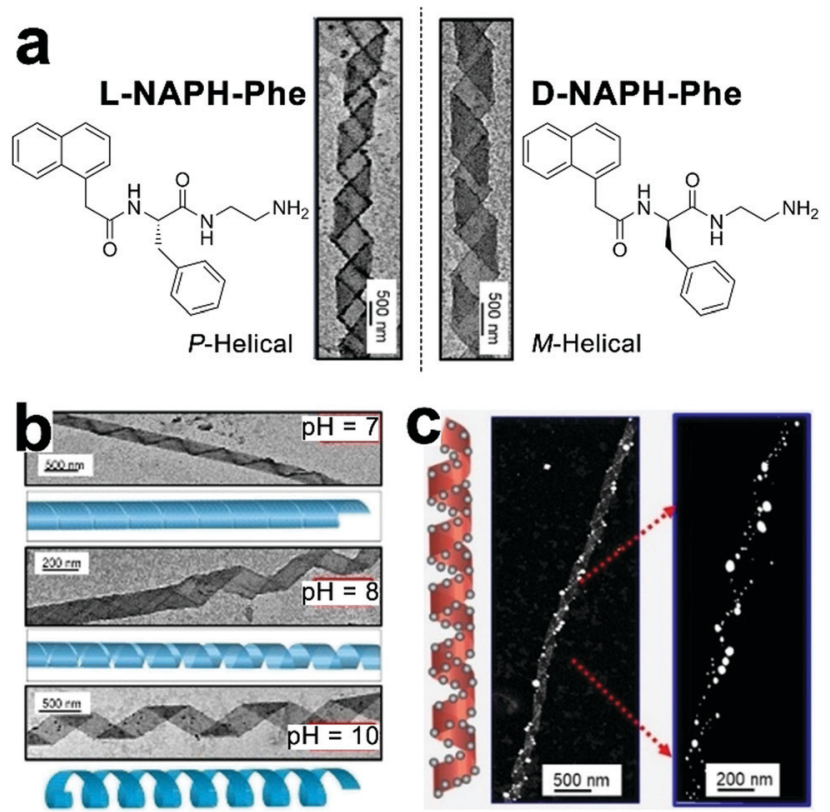

Fig. 13 (a) Chemical structures of enantiomeric amphiphiles L-NAPH-Phe and D-NAPH-Phe. Self-assembled L-NAPH-Phe and D-NAPH-Phe were treated with dopamine at $\mathrm{pH} 10$, forming $(P)$-helical PDA/L-NAPH-Phe tapes and (M)-helical PDA/D-NAPH-Phe tapes, respectively. (b) $\mathrm{pH}$ Controlled deformation of PDA-coated helical tapes. (c) The helical arrangement of AgNPs along the edge of helical tapes at $\mathrm{pH}$ 10. Reproduced with permission from ref. 190. Copyright 2019 Wiley-VCH.

composites was highly tunable by modulating the ratio of incorporated proteins (Fig. 14). ${ }^{193}$ The incorporation of fluorescent proteins started with the co-incubation of $\beta$-sheet-modified green fluorescent proteins (GFP- $\beta$ tail) with $\beta$-sheet-forming peptides (QQKFQFQFEQQ, Q11) at physiologic pH (Fig. 14a). As the peptide tail of GFP- $\beta$ tail had slow fibrillization kinetics, GFP- $\beta$ tail underwent a gradual transition from $\alpha$-helix to $\beta$-sheet upon incubating with Q11. After co-incubation, the resulting GFP- $\beta$ tail/Q11 nanofibers were sedimented by centrifugation and exhibited tunable fluorescence whose emission intensity was proportional to the concentration of GFP- $\beta$ tail relative to Q11 at the onset of incubation.

It is noteworthy that due to the non-specific interaction between protein cargos and peptidic fibrils, other $\beta$-sheetforming peptides in addition to Q11 were able to co-assemble with mutated GFP-ßtail, whose peptidic tails incapable of inserting into growing fibrils, which suggested the generality, yet empiricism to some extent, of this protein integration strategy. After demonstrating the co-assembly of GFP- $\beta$ tail and Q11, another two $\beta$-sheet-tailed fluorescent proteins, eGFP- $\beta$ tail and dsRED- $\beta$ tail, were successfully integrated with growing Q11 nanofibers to achieve blue and red fibrillar composites, respectively. Under mild agitation, resulting nanofibers with different colors were associated into microgels at predetermined ratios to produce composites with various fluorescent colors including pink, orange, and turquoise (Fig. 14b). Finally, statistically mixing $\beta$-sheet-forming peptides with $\beta$-sheet-modified fluorescent proteins was further applied

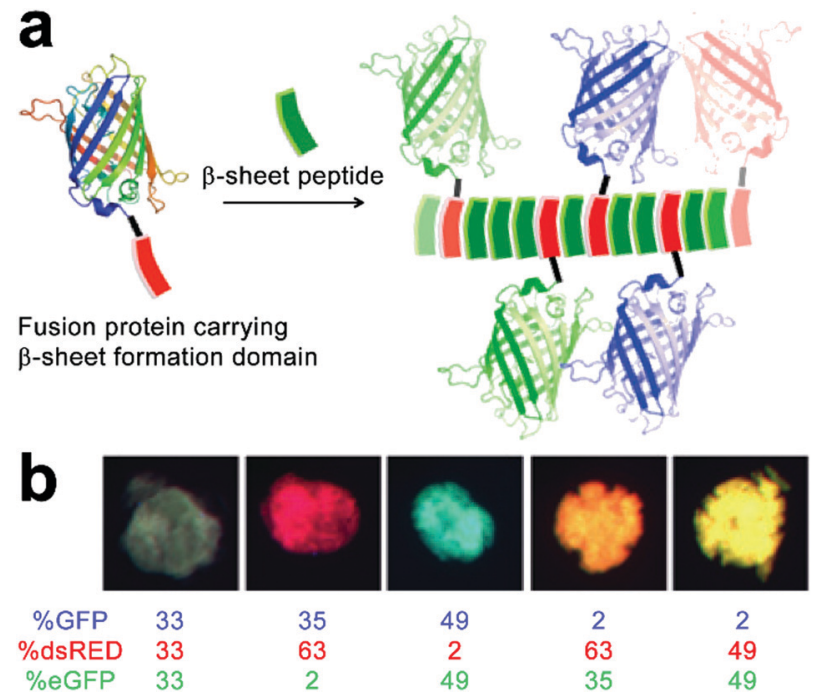

Fig. 14 (a) Schematic illustration of the incorporation of fusion proteins consisting of $\beta$-sheet formation domains into growing $\beta$-sheet nanofibers, which generate peptide nanofibers carrying multiple fluorescent proteins in precisely controlled ratios. (b) Modulating the colour of fibrillar microgels by changing the relative molar ratio of various fluorescent protein/Q11 peptide nanofibers. Adapted with permission from Macmillan Publishers Ltd: Nat. Mater., from ref. 193, copyright 2014.

on the incorporation of other functional fusion proteins to achieve adjustable enzymatic activities and antibody responses. ${ }^{193}$

The charged surface of some peptide-based nanostructures provides abundant binding sites for multiple enzymes capable of sequential chemical conversions, thereby creating peptidic nano assemblies integrated with multienzyme cascades. ${ }^{194}$ Tibita, Parquette and co-workers immobilized $\mathrm{CO}_{2}$-fixing enzyme, RubisCO, and the associated assimilatory pathway enzymes of carbon fixation upon self-assembled Ac-KK(CPT)$\mathrm{NH}_{2}$ or $\mathrm{NH}_{2}-\mathrm{KK}(\mathrm{CPT})-\mathrm{NH}_{2}$ nanotubes (Fig. 15). These enzymeloaded peptide nanotubes produced ribulose 1,5-bisphosphate (RuBP), the substrate for RubisCO, from ribose-5-phosphate (R-5-P) or glucose and continued the subsequent $\mathrm{CO}_{2}$-fixation catalyzed by RubisCO to yield the product as 3-phosphoglyceric acid (3-PGA). ${ }^{195}$ Due to the positively charged surface of nanotubes, form II $\mathrm{L}_{2}$ dimeric RubisCO (from Rhodospirillum rubrum, RubisCO II) or form $\mathrm{I}_{8} \mathrm{~S}_{8}$ hexadecameric RubisCO (from Ralstonia eutropha, RubisCO I) were able to be deposited on the nanotube surface through electrostatic interactions. ${ }^{11}$ The RubisCO enzymes were tagged with gold nanoparticles to render these enzymes observable by TEM imaging (Fig. 15c). In the resulting enzyme-nanotube hybrids, RubisCO II immobilized on $\mathrm{NH}_{2}-\mathrm{KK}(\mathrm{CPT})-\mathrm{NH}_{2}$ nanotubes exhibited much-enhanced resilience toward proteolysis, as RubisCO II enzymes embedded in nanotubes were sequestered from protease. Moreover, RubisCO I immobilized on $\mathrm{NH}_{2}-\mathrm{KK}(\mathrm{CPT})$ $\mathrm{NH}_{2}$ nanotubes exhibited a significantly enhanced selectivity toward $\mathrm{CO}_{2}$ from $\mathrm{O}_{2}$, which was attributed to the electrochemical microenvironment of immobilized RubisCO I preferentially occluded paramagnetic $\mathrm{O}_{2}$ molecules from entering its active sites. ${ }^{195}$ 

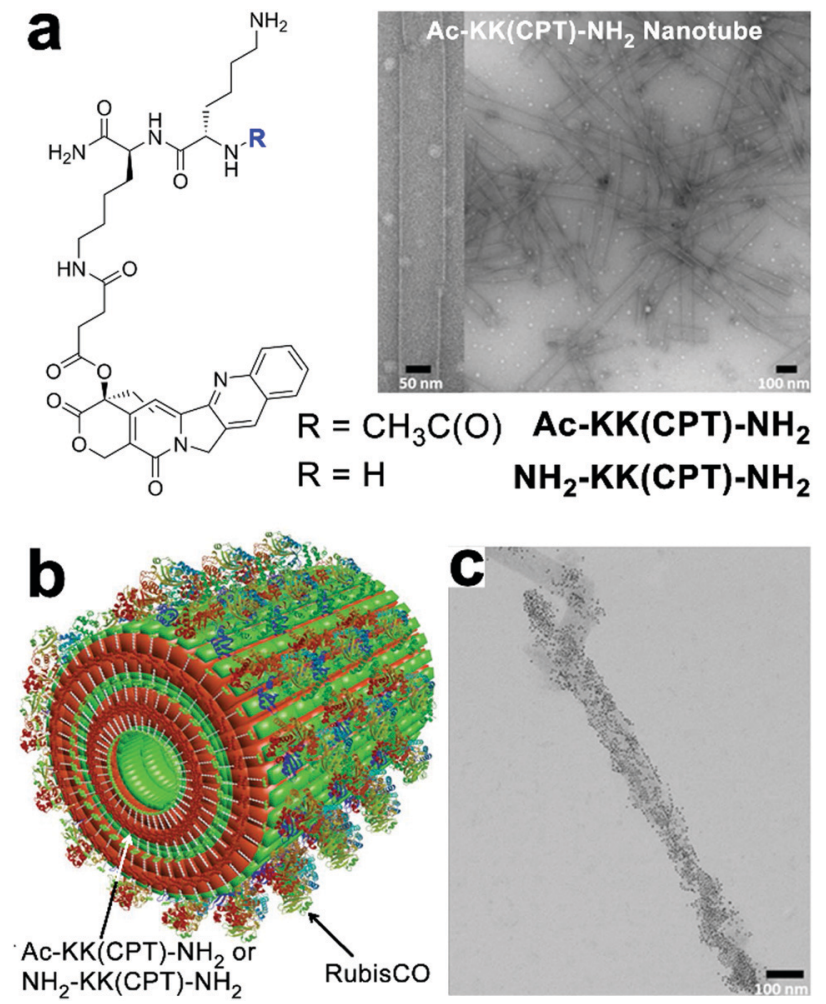

Fig. 15 (a) Chemical structures of dipeptide-conjugates Ac-KK(CPT)- $\mathrm{NH}_{2}$ and $\mathrm{NH}_{2}-\mathrm{KK}(\mathrm{CPT})-\mathrm{NH}_{2}$ and the TEM images of $\mathrm{AC}-\mathrm{KK}(\mathrm{CPT})-\mathrm{NH}_{2}$ nanotubes assembled in Bicine buffer. (b) Illustration of Rubis $\mathrm{CO}$ deposited on Ac-KK(CPT) $-\mathrm{NH}_{2} / \mathrm{NH}_{2}-\mathrm{KK}(\mathrm{CPT})-\mathrm{NH}_{2}$ nanotubes through electrostatic interactions. (c) TEM images of gold-nanoparticle-tagged RubisCO I immobilized on Ac-KK(CPT)- $\mathrm{NH}_{2}$ nanotubes. Adapted from ref. 195 with permission. Copyright 2017, Springer Nature.

\subsection{Serving as drug carriers}

Owing to the inherent biocompatibility of peptidic assemblies, they have been extensively studied as drug carriers to accommodate the complicate extracellular environment under therapeutic conditions. Natural amphipathic peptide sequences capable of forming $\beta$-sheets often comprise alternatingly arranged hydrophobic and hydrophilic residues, ${ }^{8}$ likewise, many assembling peptide amphiphiles contain conjugated alkyl segments that serve as the hydrophobic drug loading domain. Upon selfassembly, the alkyl segments are embedded in the peptidic periphery and sequestered from water, thus creating a hydrophobic phase to noncovalently entrap drug molecules lacking water solubility. ${ }^{12,196,197}$ To further improve the structural stability of drug-loaded peptide nanoassemblies and guarantee the reproducibility in their loading contents, drug molecules are covalently attached with assembling peptide amphiphiles to achieve therapeutic peptide conjugates as nanomedicines. ${ }^{11,198-201}$

Cui and co-workers constructed anticancer drug amphiphiles by conjugating four camptothecin (CPT) molecules with various $\beta$-sheet-forming sequences (GNNQQNY) bearing diglutamic acid (CPT-Sup35-E E $_{2}$ or dilysine (CPT-Sup35- $\mathrm{K}_{2}$ ) residues on the C-terminal (Fig. 16). ${ }^{198}$ The resulting therapeutic amphiphiles CPT-Sup35- $\mathrm{E}_{2}$ and CPT-Sup35- $\mathrm{K}_{2}$ individually assembled into nanofilaments with diameters $\sim 6 \mathrm{~nm}$. In contrast, mixing

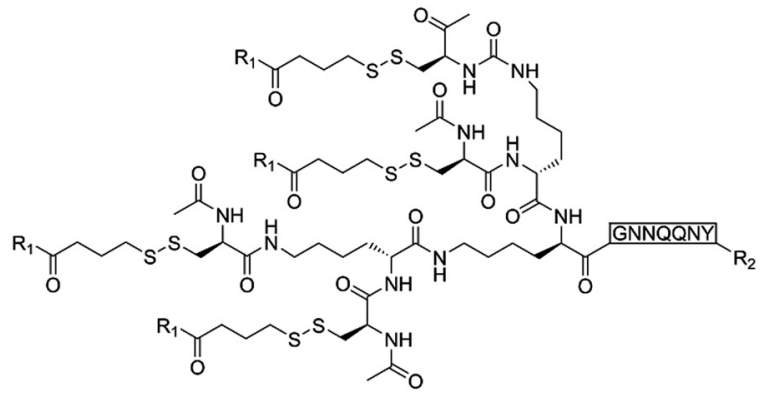
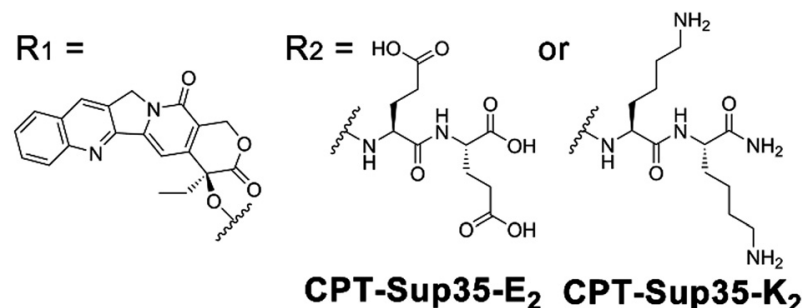

Fig. 16 Chemical structures of CPT-bearing amphiphiles CPT-Sup35- $E_{2}$ and CPT-Sup35- $\mathrm{K}_{2}$.

oppositely charged CPT-Sup35- $\mathrm{E}_{2}$ and CPT-Sup35- $\mathrm{K}_{2}$ at molar ratio $3: 1(\mathrm{n} / \mathrm{n})$ produced their co-assembled structures as nanotubes with external diameters of $\sim 123 \mathrm{~nm}$ and wall thicknesses of $\sim 25 \mathrm{~nm}$. The large hydrophobic segments of CPT-Sup35- $\mathrm{E}_{2}$ and CPT-Sup35- $\mathrm{K}_{2}$ containing four CPT molecules were crucial to creating the packing geometry of curved nanotube walls, in contrast, their amphiphilic analogues with only one or two CPT appendants were incapable of forming tubular structures. Additionally, decreasing the concentration of amphiphile mixture revealed not fully developed nanotubes as helical ribbons, which demonstrated that the growth of nanotubes underwent the widening of helical precursors. Although the unfavorable dimension and surface charge of CPT nanotubes in this study prohibited their administration on tumor-bearing mice through tail-vein injection, locally injected CPT-bearing amphiphilic nanotubes exhibited a prolonged retention time on tumor sites, which may support the sustainable CPT release benefitting the local tumor treatment. ${ }^{198}$

\subsection{Photophysical processes regulated by the spatial arrangement of chromophores}

Within photonic/electronic nanostructures, effective and long-range charge delocalization is a direct consequence of the supramolecular arrangement of chromophores. Accordingly, electron donors and/or acceptors have been conjugated with assembling peptides to construct semiconductive hydrogels. ${ }^{26,98}$ With the formation of peptide frameworks, conjugated donor and acceptor chromophores are positioned into nanostructures with high spatial precision. Resembling the organized lightharvesting chromophores within bacteria and green plants capable of photosynthesis, electron donors (p-type) and acceptors (n-type) organized by assembling peptides can replicate their natural counterparts to support highly efficient photophysical energy-/electron-transfer events. ${ }^{13,20,202,203}$ 
Ulijn and coworkers synthesized an n-type naphthalenediimidedipeptide conjugate acceptor, NDI-YF- $\mathrm{NH}_{2}$, thorough the thermolysin-catalyzed condensation between NDI-tyrosine (NDI-Y) and phenylalanine amide $\left(\mathrm{F}-\mathrm{NH}_{2}\right)$ (Fig. 17a). ${ }^{204}$ This enzymatic amide condensation is reversible, which permits the exchange of $\mathrm{F}-\mathrm{NH}_{2}$ by various amino acid amide derivatives and thereby generating a dynamic peptide library capable of self-assembly. ${ }^{205-207}$ While the peptide bonds within these n-type NDI-appended peptide conjugates were of a dynamic nature, the consequent amide hydrolysis was able to be mitigated by forming alternating stacks with p-type donor chromophores, such as 1,5-dialkoxy naphthalene (1,5-DAN) (Fig. 17a) ${ }^{204,207}$ Because this alternate donor-acceptor stacking generated strong charge-transfer interactions, which was reasoned to produce favorable free energy change to attenuate the enzymatic amide bond exchange. ${ }^{207}$ In addition, the closely packed donor-acceptor chromophores in alternating fashion allowed long-range charge delocalization, which resulted in the significant enhancement in conductivity of resulting co-assembled nanostructures.

Tovar, Adams, and coworkers synthesized two peptidic $\pi$-electron conjugates: oligo( $p$-phenylenevinylene) flanked by $\beta$-sheet-forming peptides, OPV3, and quaterthiophene flanked by naphthalenediimide-appended peptides, OT4-NDI (Fig. 17b). As these two peptidic $\pi$-electron conjugates had different $\mathrm{p} K_{\mathrm{a}}$, controlling the rate of acidification on their mixture triggered the gelation of these two conjugates stepwise or simultaneously, which produced self-sorted or co-assembled hydrogel networks, respectively. ${ }^{20}$ In order to avoid the instant $\mathrm{pH}$ decrease by adding $\mathrm{HCl}$, the slow hydrolysis of glucono- $\delta$-lactone (GdL) was employed to achieve gradual acidification on the assembling conjugates. With the hydrolysis of GdL, ionized carboxylic groups on OT4-NDI with a larger $\mathrm{p} K_{\mathrm{a}}$ were further protonated than OPV3, which accordingly induced the preceding gelation of OT4-NDI. Therefore, GdL hydrolysis-induced acidification triggered the orthogonal assembly of OPV3 and OT4-NDI in the presence of each other, which eventually produced a self-sorted gelation network from their binary mixture. In contrast to hydrolysis-induced acidification, adding $\mathrm{HCl}$ caused absolute protonation and charge screening on all peptidic conjugates immediately, which in turn yielded the co-assembled network containing both OPV3 and OT4-NDI in a random arrangement. Comparing with the self-sorted network, coassembled OPV3 and OT4-NDI supported more efficient energy-/electron-transfer from oligo( $p$-phenylenevinylene) to quaterthiophene and naphthalenediimide chromophores, demonstrating the influence of spatial organization of chromophores on the photophysical processes within nanoassemblies. ${ }^{20}$

\subsection{Integrating artificial photosynthesis with peptide nanotubes}

Diphenylalanine (FF) can spontaneously assemble into highaspect-ratio nanotubes that may serve as stable supramolecular frameworks to template the deposition of extra-functional constituents on the nanotube surface. ${ }^{208}$ Park and co-workers created artificial light-harvesting hybrids by depositing
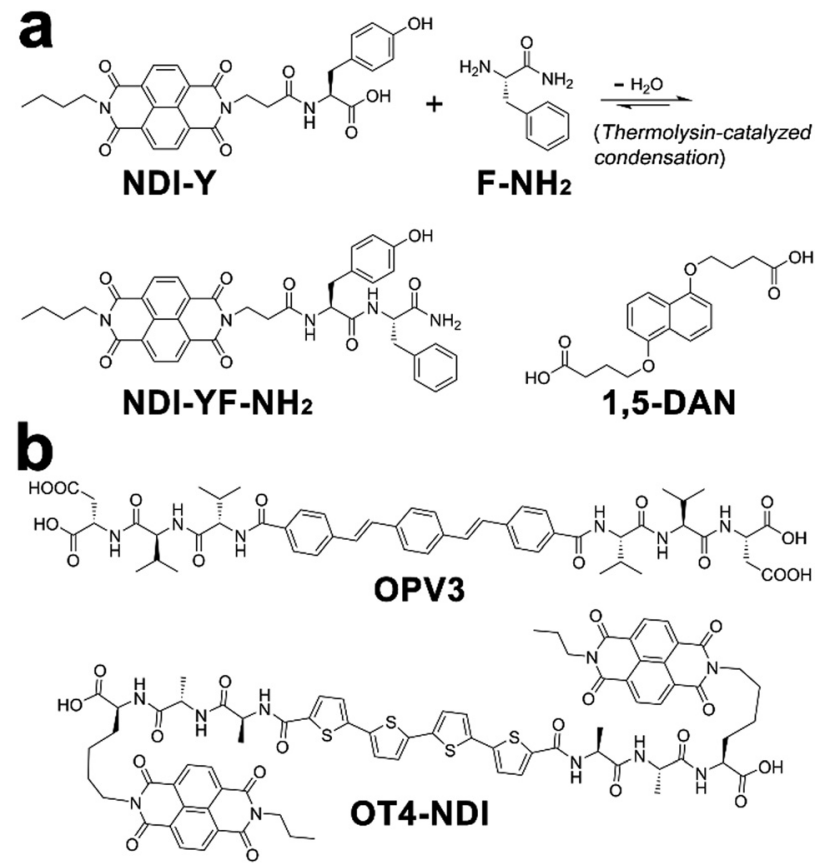

Fig. 17 Chemical structures of donor and acceptor peptide conjugate pairs: (a) NDI-YF-NH $2 / 1,5-D A N$, (b) OPV3/OT4-NDI.

$\mathrm{J}$-aggregates of tetra( $p$-hydroxyphenyl) porphyrin (THPP) and platinum nanoparticles (PtNPs) on the surface of selfassembled FF nanotubes (Fig. 18). Given the high specific surface area of resulting nanohybrids, THPP and PtNPs immobilized on nanotube surface participated in the formation of biomimetic redox gradient, which established the chemical basis of artificial photosynthesis (Fig. 18). ${ }^{209}$ The preparation of light-harvesting hybrids started from mixing molecularly dissolved FF and THPP in 1,1,1,3,3,3-hexa-fluoro-2-propanol (HFIP), which was then diluted by phosphate buffer ( $\mathrm{pH}$ 6.0) to induce coaggregation of FF and THPP as a green precipitate. The absorption spectra of the resulting FF/THPP precipitate exhibited a prominent red-shift from monomeric THPP, demonstrating the J-aggregation of protonated THPP $\left(\mathrm{H}_{2} \mathrm{THPP}^{2+}\right)$ in the FF/THPP hybrid which was also consistent with the rough THPP coating on FF nanotubes. Assuming the negatively charged surface of FF nanotubes bound protonated

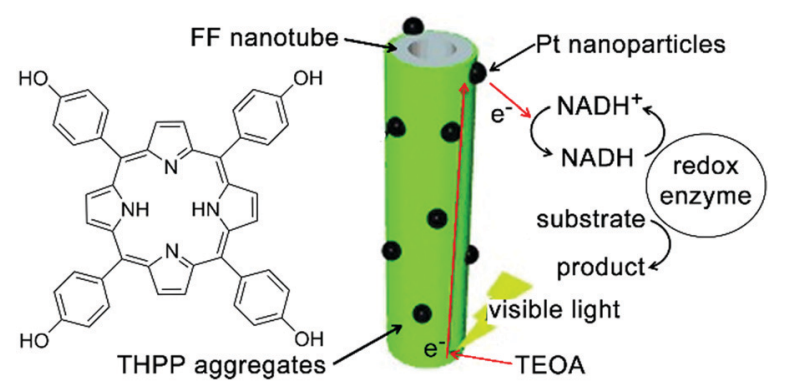

Fig. 18 Light-harvesting peptide nanotubes capable of artificial photosynthesis. Figure adapted with permission from ref. 209. Copyright 2012 Wiley-VCH. 
THPP aggregates through electrostatic interactions, ${ }^{210}$ the metal precursor $\left(\mathrm{K}_{2} \mathrm{PtCl}_{4}\right)$ mixed with $\mathrm{FF} / \mathrm{THPP}$ was photoreduced to PtNPs to generate the ternary $\mathrm{FF} / \mathrm{THPP} / \mathrm{PtNPs}$ hybrids. Within the ternary hybrids, THPP aggregates and PtNPs supported strong exciton coupling and efficient charge separation, respectively. Therefore, the FF/THPP/PtNPs hybrid enabled consecutive electron transfer from the starting electron donor, triethanolamine (TEOA), to THPP, then to PtNPs and finally reached the electron mediator $\left(\left[\mathrm{Cp}^{*} \mathrm{Rh}(\mathrm{bpy})\left(\mathrm{H}_{2} \mathrm{O}\right)\right]^{2+}\right.$, $\mathrm{Cp}^{*}=\mathrm{C}_{5} \mathrm{Me}_{5}$, bpy $=2,2^{\prime}$-bipyridine). Moreover, to simulate the photophysical process in photosystem I, the artificial photosystem in this study was coupled with $\mathrm{NADH}$ regeneration to drive the enzymatic conversion (glutamate dehydrogenase) of $\alpha$-ketoglutarate to L-glutamate upon visible light exposure. ${ }^{209}$

\subsection{Supercapacitor electrodes constructed by peptide nanotubes}

Electron-rich moieties conjugated with peptides can be positioned into densely arranged nanostructures along with the self-assembly of peptides. These organized moieties in proximity may support the delocalization of $\pi$-electrons, which underlies the semiconductivity of such peptide assemblies. ${ }^{211,212}$ Biocompatible diphenylalanine (FF) nanotubes contained quantum-confined regions for electron transfer, accordingly, biosensor electrodes decorated with FF nanotubes owned an enlarged effective surface area, which enabled ultrasensitive detection of ethanol, phenol, and antigen. ${ }^{213-215}$ Given the great success of peptide nanotubes
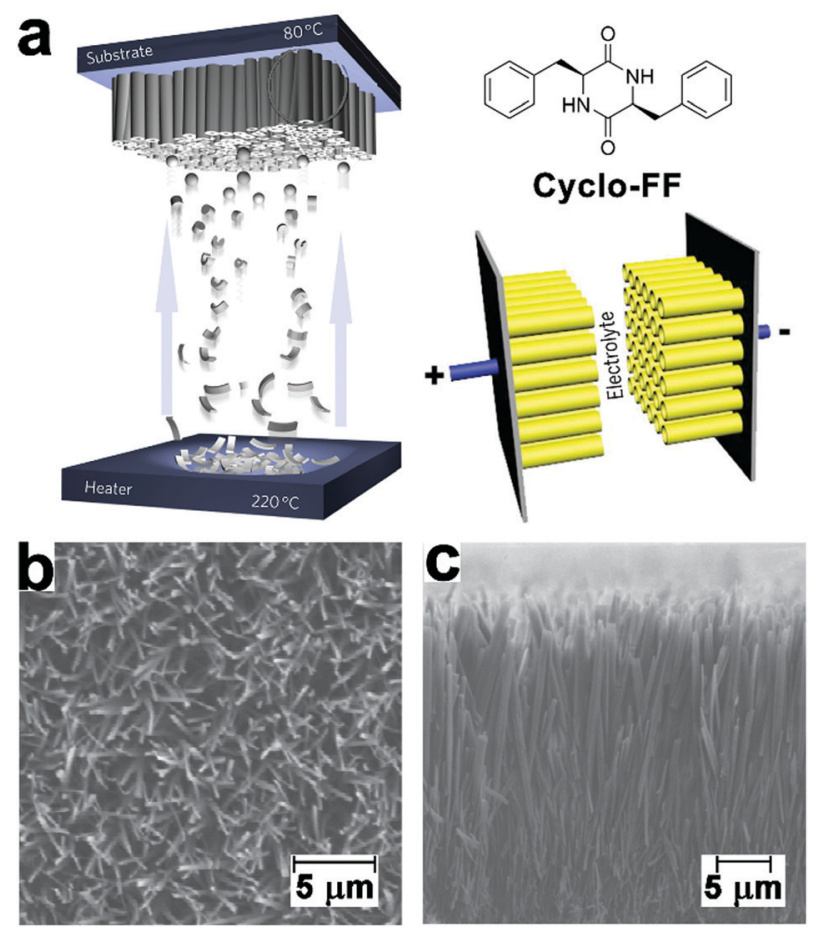

Fig. 19 (a) Preparation of supercapacitor electrodes decorated with vertically aligned cyclo-FF nanotubes through vapor deposition. (b) Top-view and (c) side-view SEM images of vertically aligned cyclo-FF nanotubes. Reproduced with permission from Macmillan Publishers Ltd: Nat. Nanotechnol., from ref. 216, copyright 2009. in the surface modification of high-surface-area electrodes, they were subsequently explored to create a patterned and homogeneous coating on the electrode of the supercapacitor to achieve bio-modified energy storage devices. ${ }^{14,216}$ Gazit, Rosenman, et al. created a dense coating of vertically aligned peptide nanotubes over supercapacitor electrodes through the vapor deposition of cyclo-diphenylalanine (cyclo-FF) (Fig. 19). ${ }^{216}$ By modulating the supply of cyclo-FF for deposition, aromatic peptide nanotubes grew into nanoforests with tunable height over electrode surface, thereby producing high-surface-area supercapacitor electrodes (Fig. 19b). The dense and homogeneous alignment of peptide nanotubes significantly enlarged the interface between electrode and electrolyte solution, resulting in a larger capacitance than capacitors constituted by standard or CNT-modified carbon electrodes. Moreover, the highly reproducible electrostatic charge/ discharge processes of such nanotube-modified supercapacitors suggested their structural stability and excellent endurance toward potential sweeps.

\section{Conclusions and perspectives}

Benefiting from the diversity of chemical composition, multicomponent nanocomposites can be imparted with greater tunability and synergism on their hierarchical structures, thus more closely replicate the functional competence of naturally occurring materials and organisms. In the review, we have illustrated the fundamental kinetic and thermodynamic principles of supramolecular polymerization, which establish various strategies to construct multi-component nanostructures from amphiphilic building blocks. Most of these strategies involve monomers consisting of assembling peptide factors, which accordingly generate supramolecular frameworks to regulate the following incorporation of functional components. Moreover, these strategies enable the incorporation of every individual component with high spatial precision, therefore, producing well-defined nanocomposites whose functional competence originates from the synergistic interplay between spatially organized constituents.

Despite tremendous advancements in the construction of peptide-based nanohybrids, studies on multicomponent assembly largely remain as semi-empirical exploring. Resembling classic supramolecular systems, peptide-based structures are commonly prepared in solution. Peptidic monomers retain their spatially defined aggregation by one or more noncovalent interactions, including hydrogen bonding, $\pi$-stacking, hydrophobic effects, and charge-transfer interactions. The strength of these noncovalent interactions, typically within $10-100 \mathrm{~kJ} \mathrm{~mol}^{-1}, 217$ is similar to those between solute and solvent, which renders the microstructure of peptide-based nanocomposites highly fluxional toward external factors and stimuli. ${ }^{49}$ Particularly, in contrast to synthetic monomers assembling in organic media, the critical role of hydrophobic collapse in initiating peptide-involved assembly results in larger susceptibility of structural integrity to temperature, concentration, and other instinct properties of aqueous solvents. Therefore, revisiting the knowledge of physical 
chemistry provides us new insights into the relationship between solute and solvent that correlates with self-assembly. ${ }^{218,219}$

Moreover, recent progress of supramolecular polymerization brings new theoretical models to unravel the coassembly mechanism of multicomponent system. ${ }^{30-32,38}$ Quantitative spectroscopic studies, including UV, CD, and fluorescence, combined with morphology imaging through AFM, TEM, and/ or super-resolution fluorescence microscopy, set up powerful experimental techniques to resolve the composition of complex coassembly system. Hopefully, future efforts will convert current heuristic studies of peptide-involved assembly to stoichiometric and designable research, which eventually enables us to unambiguously interpret the correlation between monomer structure, arrangement of aggregated species, and functioning of the resulting materials.

\section{Conflicts of interest}

There are no conflicts to declare.

\section{Acknowledgements}

This work was supported by Jiangsu University Grant (No. 20JDG31).

\section{Notes and references}

1 M. J. Webber, E. A. Appel, E. Meijer and R. Langer, Nat. Mater., 2016, 15, 13-26.

2 M. R. Begley, D. S. Gianola and T. R. Ray, Science, 2019, 364, eaav4299.

3 M. Pishvar and R. L. Harne, Adv. Sci., 2020, 7, 2001384.

4 L. Adler-Abramovich and E. Gazit, Chem. Soc. Rev., 2014, 43, 6881-6893.

5 S. H. Kim and J. R. Parquette, Nanoscale, 2012, 4, 6940-6947.

6 C. Liang, R. Ni, J. E. Smith, W. S. Childers, A. K. Mehta and D. G. Lynn, J. Am. Chem. Soc., 2014, 136, 15146-15149.

7 M.-C. Hsieh, C. Liang, A. K. Mehta, D. G. Lynn and M. A. Grover, J. Am. Chem. Soc., 2017, 139, 17007-17010.

8 D. M. Raymond and B. L. Nilsson, Chem. Soc. Rev., 2018, 47, 3659-3720.

9 J. R. Clegg, A. M. Wagner, S. R. Shin, S. Hassan, A. Khademhosseini and N. A. Peppas, Prog. Mater. Sci., 2019, 106, 100589.

10 Y. Wang, L. Cao, S. Guan, G. Shi, Q. Luo, L. Miao, I. Thistlethwaite, Z. Huang, J. Xu and J. Liu, J. Mater. Chem., 2012, 22, 2575-2581.

11 S. H. Kim, J. A. Kaplan, Y. Sun, A. Shieh, H. L. Sun, C. M. Croce, M. W. Grinstaff and J. R. Parquette, Chem. Eur. J., 2015, 21, 101-105.

12 S. Soukasene, D. J. Toft, T. J. Moyer, H. Lu, H.-K. Lee, S. M. Standley, V. L. Cryns and S. I. Stupp, ACS Nano, 2011, 5, 9113-9121.

13 K. J. Channon, G. L. Devlin and C. E. MacPhee, J. Am. Chem. Soc., 2009, 131, 12520-12521.
14 P. Beker, I. Koren, N. Amdursky, E. Gazit and G. Rosenman, J. Mater. Sci., 2010, 45, 6374-6378.

15 R. N. Perham, Philos. Trans. R. Soc. London, Ser. B, 1975, 272, 123-136.

16 R. E. Blankenship, Chemiosmotic coupling and ATP synthesis, John Wiley \& Sons, 2nd edn, 2014, ch. 8, pp. 133-143.

17 J. F. Allen, Cell, 2002, 110, 273-276.

18 J.-M. Lehn, Science, 2002, 295, 2400-2403.

19 B. O. Okesola and A. Mata, Chem. Soc. Rev., 2018, 47, 3721-3736.

20 H. A. M. Ardoña, E. R. Draper, F. Citossi, M. Wallace, L. C. Serpell, D. J. Adams and J. D. Tovar, J. Am. Chem. Soc., 2017, 139, 8685-8692.

21 J. D. Tovar, Bioinspiration Biomimetics, 2017, 13, 015004.

22 R. Bhosale, J. Míšek, N. Sakai and S. Matile, Chem. Soc. Rev., 2010, 39, 138-149.

23 P. Makam and E. Gazit, Chem. Soc. Rev., 2018, 47, 3406-3420. 24 H. Kar and S. Ghosh, Isr. J. Chem., 2019, 59, 881-891.

25 S. Tu, S. H. Kim, J. Joseph, D. A. Modarelli and J. R. Parquette, J. Am. Chem. Soc., 2011, 133, 19125-19130.

26 J. Raeburn and D. J. Adams, Chem. Commun., 2015, 51, 5170-5180.

27 E. R. Draper and D. J. Adams, Chem. Soc. Rev., 2018, 47, 3395-3405.

28 M. M. Safont-Sempere, G. Fernández and F. Würthner, Chem. Rev., 2011, 111, 5784-5814.

29 B. Adelizzi, A. Aloi, A. J. Markvoort, H. M. Ten Eikelder, I. K. Voets, A. R. Palmans and E. Meijer, J. Am. Chem. Soc., 2018, 140, 7168-7175.

30 P. A. Korevaar, T. F. de Greef and E. Meijer, Chem. Mater., 2014, 26, 576-586.

31 B. Adelizzi, N. J. Van Zee, L. N. de Windt, A. R. Palmans and E. Meijer, J. Am. Chem. Soc., 2019, 141, 6110-6121.

32 M. Wehner and F. Würthner, Nat. Rev. Chem., 2019, 38-53.

33 G. Ghosh, P. Dey and S. Ghosh, Chem. Commun., 2020, 56, 6757-6769.

34 T. F. De Greef, M. M. Smulders, M. Wolffs, A. P. Schenning, R. P. Sijbesma and E. Meijer, Chem. Rev., 2009, 109, 5687-5754.

35 Z. Chen, A. Lohr, C. R. Saha-Möller and F. Würthner, Chem. Soc. Rev., 2009, 38, 564-584.

36 J. Matern, Y. Dorca, L. Sánchez and G. Fernandez, Angew. Chem., Int. Ed., 2019, 58, 16730-16740.

37 D. van der Zwaag, T. F. de Greef and E. Meijer, Angew. Chem., Int. Ed., 2015, 54, 8334-8336.

38 P. A. Korevaar, S. J. George, A. J. Markvoort, M. M. Smulders, P. A. Hilbers, A. P. Schenning, T. F. De Greef and E. Meijer, Nature, 2012, 481, 492-496.

39 P. A. Korevaar, C. Schaefer, T. F. de Greef and E. Meijer, J. Am. Chem. Soc., 2012, 134, 13482-13491.

40 G. Fernandez, M. Stolte, V. Stepanenko and F. Wuerthner, Chem. - Eur. J., 2013, 19, 206-217.

41 V. Stepanenko, X. Q. Li, J. Gershberg and F. Würthner, Chem. - Eur. J., 2013, 19, 4176-4183.

42 W. Zhang, W. Jin, T. Fukushima, A. Saeki, S. Seki and T. Aida, Science, 2011, 334, 340-343. 
43 A. Sandeep, V. K. Praveen, K. K. Kartha, V. Karunakaran and A. Ajayaghosh, Chem. Sci., 2016, 7, 4460-4467.

44 W. Zhang, W. Jin, T. Fukushima, T. Mori and T. Aida, J. Am. Chem. Soc., 2015, 137, 13792-13795.

45 Z. Yu, F. Tantakitti, T. Yu, L. C. Palmer, G. C. Schatz and S. I. Stupp, Science, 2016, 351, 497-502.

46 N. Kameta and W. Ding, Bull. Chem. Soc. Jpn., 2019, 92, 1053-1059.

47 R. V. Ulijn and A. M. Smith, Chem. Soc. Rev., 2008, 37, 664-675.

48 A. L. Boyle and D. N. Woolfson, Chem. Soc. Rev., 2011, 40, 4295-4306.

49 M. F. Mabesoone, A. R. Palmans and E. Meijer, J. Am. Chem. Soc., 2020, 142, 19781-19798.

50 A. Nandakumar, Y. Ito and M. Ueda, J. Am. Chem. Soc., 2020, 142, 20994-21003.

51 J. Wang, K. Liu, R. Xing and X. Yan, Chem. Soc. Rev., 2016, 45, 5589-5604.

52 Y. Loo, S. Zhang and C. A. Hauser, Biotechnol. Adv., 2012, 30, 593-603.

53 D. Görl and F. Würthner, Angew. Chem., Int. Ed., 2016, 55, 12094-12098.

54 P. P. Syamala, B. Soberats, D. Görl, S. Gekle and F. Würthner, Chem. Sci., 2019, 10, 9358-9366.

55 P. P. Syamala and F. Würthner, Chemistry, 2020, 26, 8426-8434.

56 M. Hartlieb, E. D. Mansfield and S. Perrier, Polym. Chem., 2020, 11, 1083-1110.

57 T. Heek, C. Fasting, C. Rest, X. Zhang, F. Würthner and R. Haag, Chem. Commun., 2010, 46, 1884-1886.

58 F. Würthner, Acc. Chem. Res., 2016, 49, 868-876.

59 S. Ogi, V. Stepanenko, K. Sugiyasu, M. Takeuchi and F. Würthner, J. Am. Chem. Soc., 2015, 137, 3300-3307.

60 S. Ogi, V. Stepanenko, J. Thein and F. Würthner, J. Am. Chem. Soc., 2016, 138, 670-678.

61 T. P. Knowles, C. A. Waudby, G. L. Devlin, S. I. Cohen, A. Aguzzi, M. Vendruscolo, E. M. Terentjev, M. E. Welland and C. M. Dobson, Science, 2009, 326, 1533-1537.

62 S. I. Cohen, S. Linse, L. M. Luheshi, E. Hellstrand, D. A. White, L. Rajah, D. E. Otzen, M. Vendruscolo, C. M. Dobson and T. P. Knowles, Proc. Natl. Acad. Sci. U. S. A., 2013, 110, 9758-9763.

63 A. Levin, T. O. Mason, L. Adler-Abramovich, A. K. Buell, G. Meisl, C. Galvagnion, Y. Bram, S. A. Stratford, C. M. Dobson and T. P. Knowles, Nat. Commun., 2014, $5,5219$.

64 C. Chen, J. Tan, M.-C. Hsieh, T. Pan, J. T. Goodwin, A. K. Mehta, M. A. Grover and D. G. Lynn, Nat. Chem., 2017, 9, 799-804.

65 M.-C. Hsieh, D. G. Lynn and M. A. Grover, J. Phys. Chem. B, 2017, 121, 7401-7411.

66 A. Pal, M. Malakoutikhah, G. Leonetti, M. Tezcan, M. Colomb-Delsuc, V. D. Nguyen, J. van der Gucht and S. Otto, Angew. Chem., Int. Ed., 2015, 54, 7852-7856.

67 M. Colomb-Delsuc, E. Mattia, J. W. Sadownik and S. Otto, Nat. Commun., 2015, 6, 7427.
68 S. Onogi, H. Shigemitsu, T. Yoshii, T. Tanida, M. Ikeda, R. Kubota and I. Hamachi, Nat. Chem., 2016, 8, 743.

69 P. A. Korevaar, C. J. Newcomb, E. Meijer and S. I. Stupp, J. Am. Chem. Soc., 2014, 136, 8540-8543.

70 F. Tantakitti, J. Boekhoven, X. Wang, R. V. Kazantsev, T. Yu, J. Li, E. Zhuang, R. Zandi, J. H. Ortony, C. J. Newcomb, L. C. Plamer, G. S. Shekhawat, M. O. de la Cruz, G. C. Schatz and S. I. Stupp, Nat. Mater., 2016, 15, 469-476.

71 C. Yuan, A. Levin, W. Chen, R. Xing, Q. Zou, T. W. Herling, P. K. Challa, T. P. Knowles and X. Yan, Angew. Chem., 2019, 131, 18284-18291.

72 S. Ogi, K. Sugiyasu, S. Manna, S. Samitsu and M. Takeuchi, Nat. Chem., 2014, 6, 188-195.

73 W. Wagner, M. Wehner, V. Stepanenko, S. Ogi and F. Würthner, Angew. Chem., Int. Ed., 2017, 56, 16008-16012.

74 S. Ogi, K. Matsumoto and S. Yamaguchi, Angew. Chem., Int. Ed., 2018, 57, 2339-2343.

75 M. Wehner, M. I. S. Röhr, M. Bühler, V. Stepanenko, W. Wagner and F. Würthner, J. Am. Chem. Soc., 2019, 141, 6092-6107.

76 C. Jarrett-Wilkins, X. He, H. E. Symons, R. L. Harniman, C. F. Faul and I. Manners, Chem. - Eur. J., 2018, 24, 15556-15565.

77 J. van Herrikhuyzen, A. Syamakumari, A. P. Schenning and E. Meijer, J. Am. Chem. Soc., 2004, 126, 10021-10027.

78 M. M. Smulders, M. M. Nieuwenhuizen, T. F. de Greef, P. van der Schoot, A. P. Schenning and E. A. W. Meijer, Chem. - Eur. J., 2010, 16, 362-367.

79 X.-Q. Li, V. Stepanenko, Z. Chen, P. Prins, L. D. Siebbeles and F. Würthner, Chem. Commun., 2006, 3871-3873.

80 D. Zhao and J. S. Moore, Org. Biomol. Chem., 2003, 1, 3471-3491.

81 S. Ogi, T. Fukui, M. L. Jue, M. Takeuchi and K. Sugiyasu, Angew. Chem., Int. Ed., 2014, 53, 14363-14367.

82 M. M. Bouman and E. Meijer, Adv. Mater., 1995, 7, 385-387.

83 W. DeGrado and J. Lear, J. Am. Chem. Soc., 1985, 107, 7684-7689.

84 S. Kamtekar, J. M. Schiffer, H. Xiong, J. M. Babik and M. H. Hecht, Science, 1993, 262, 1680-1685.

85 E. Gazit, FASEB J., 2002, 16, 77-83.

86 M. Reches, Y. Porat and E. Gazit, J. Biol. Chem., 2002, 277, 35475-35480.

87 R. V. Ulijn and D. N. Woolfson, Chem. Soc. Rev., 2010, 39, 3349-3350.

88 L. E. O’leary, J. A. Fallas, E. L. Bakota, M. K. Kang and J. D. Hartgerink, Nat. Chem., 2011, 3, 821-828.

89 A. Saiani, A. Mohammed, H. Frielinghaus, R. Collins, N. Hodson, C. Kielty, M. Sherratt and A. Miller, Soft Matter, 2009, 5, 193-202.

90 L. Adler-Abramovich, L. Vaks, O. Carny, D. Trudler, A. Magno, A. Caflisch, D. Frenkel and E. Gazit, Nat. Chem. Biol., 2012, 8, 701-706.

91 P. C. Ke, M.-A. Sani, F. Ding, A. Kakinen, I. Javed, F. Separovic, T. P. Davis and R. Mezzenga, Chem. Soc. Rev., 2017, 46, 6492-6531. 
92 N. L. Truex, Y. Wang and J. S. Nowick, J. Am. Chem. Soc., 2016, 138, 13882-13890.

93 S. Zhang, T. Holmes, C. Lockshin and A. Rich, Proc. Natl. Acad. Sci. U. S. A., 1993, 90, 3334-3338.

94 J. P. Schneider, D. J. Pochan, B. Ozbas, K. Rajagopal, L. Pakstis and J. Kretsinger, J. Am. Chem. Soc., 2002, 124, 15030-15037.

95 J. Gao, C. Tang, M. A. Elsawy, A. M. Smith, A. F. Miller and A. Saiani, Biomacromolecules, 2017, 18, 826-834.

96 S. Li, A. K. Mehta, A. N. Sidorov, T. M. Orlando, Z. Jiang, N. R. Anthony and D. G. Lynn, J. Am. Chem. Soc., 2016, 138, 3579-3586.

97 Y. Hu, R. Lin, P. Zhang, J. Fern, A. G. Cheetham, K. Patel, R. Schulman, C. Kan and H. Cui, ACS Nano, 2016, 10, 880-888.

98 S. Fleming and R. V. Ulijn, Chem. Soc. Rev., 2014, 43, 8150-8177.

99 A. Lampel, R. Ulijn and T. Tuttle, Chem. Soc. Rev., 2018, 47, 3737-3758.

100 R. V. Ulijn and A. Lampel, Isr. J. Chem., 2020, 60, 1129-1140.

101 M. Reches and E. Gazit, Nano Lett., 2004, 4, 581-585.

102 M. Reches and E. Gazit, Isr. J. Chem., 2005, 45, 363-371.

103 L. Adler-Abramovich, M. Reches, V. L. Sedman, S. Allen, S. J. Tendler and E. Gazit, Langmuir, 2006, 22, 1313-1320.

104 M. Reches and E. Gazit, Phys. Biol., 2006, 3, S10.

105 E. Gazit, Prion, 2007, 1, 32-35.

106 P. Tamamis, L. Adler-Abramovich, M. Reches, K. Marshall, P. Sikorski, L. Serpell, E. Gazit and G. Archontis, Biophys. J., 2009, 96, 5020-5029.

107 C. H. Görbitz, Chem. Commun., 2006, 2332-2334.

108 N. S. De Groot, T. Parella, F. X. Aviles, J. Vendrell and S. Ventura, Biophys. J., 2007, 92, 1732-1741.

109 M. J. Krysmann, V. Castelletto, A. Kelarakis, I. W. Hamley, R. A. Hule and D. J. Pochan, Biochemistry, 2008, 47, 4597-4605.

110 M. Krysmann, V. Castelletto, J. McKendrick, L. Clifton, P. Harris and S. King, Langmuir, 2008, 24, 8158-8162.

111 S. Marchesan, C. D. Easton, F. Kushkaki, L. Waddington and P. G. Hartley, Chem. Commun., 2012, 48, 2195-2197.

112 V. Jayawarna, M. Ali, T. A. Jowitt, A. F. Miller, A. Saiani, J. E. Gough and R. V. Ulijn, Adv. Mater., 2006, 18, 611-614.

113 A. M. Smith, R. J. Williams, C. Tang, P. Coppo, R. F. Collins, M. L. Turner, A. Saiani and R. V. Ulijn, Adv. Mater., 2008, 20, 37-41.

114 C. Tang, A. M. Smith, R. F. Collins, R. V. Ulijn and A. Saiani, Langmuir, 2009, 25, 9447-9453.

115 P. W. Frederix, R. V. Ulijn, N. T. Hunt and T. Tuttle, J. Phys. Chem. Lett., 2011, 2, 2380-2384.

116 I. Sasselli, C. Pappas, E. Matthews, T. Wang, N. Hunt, R. Ulijn and T. Tuttle, Soft Matter, 2016, 12, 8307-8315.

117 P. W. Frederix, G. G. Scott, Y. M. Abul-Haija, D. Kalafatovic, C. G. Pappas, N. Javid, N. T. Hunt, R. V. Ulijn and T. Tuttle, Nat. Chem., 2015, 7, 30-37.

118 G. G. Scott, P. J. McKnight, T. Tuttle and R. V. Ulijn, Adv. Mater., 2016, 28, 1381-1386.
119 Y. Fu, B. Li, Z. Huang, Y. Li and Y. Yang, Langmuir, 2013, 29, 6013-6017.

120 M. Wang, P. Zhou, J. Wang, Y. Zhao, H. Ma, J. R. Lu and H. Xu, J. Am. Chem. Soc., 2017, 139, 4185-4194.

121 Q. Xing, J. Zhang, Y. Xie, Y. Wang, W. Qi, H. Rao, R. Su and Z. He, ACS Nano, 2018, 12, 12305-12314.

122 M. L. Mason, R. F. Lalisse, T. J. Finnegan, C. M. Hadad, D. A. Modarelli and J. R. Parquette, Langmuir, 2019, 35, 12460-12468.

123 G. D. Rose, A. R. Geselowitz, G. J. Lesser, R. H. Lee and M. H. Zehfus, Science, 1985, 229, 834-838.

124 M. Avinash and T. Govindaraju, Nanoscale, 2014, 6, 13348-13369.

125 H. Moorthy, L. P. Datta and T. Govindaraju, Chem. - Asian J., 2021, 16, 423-442.

126 M. Pandeeswar, M. Avinash and T. Govindaraju, Chem. Eur. J., 2012, 18, 4818-4822.

127 M. Pandeeswar, H. Khare, S. Ramakumar and T. Govindaraju, RSC Adv., 2014, 4, 20154-20163.

128 M. Avinash, K. Swathi, K. Narayan and T. Govindaraju, ACS Appl. Mater. Interfaces, 2016, 8, 8678-8685.

129 M. Avinash and T. Govindaraju, Acc. Chem. Res., 2018, 51, 414-426.

130 B. Roy and T. Govindaraju, Bull. Chem. Soc. Jpn., 2019, 92, 1883-1901.

131 M. Avinash and T. Govindaraju, Adv. Mater., 2012, 24, 3905-3922.

132 B. J. Schwartz, Annu. Rev. Phys. Chem., 2003, 54, 141-172.

133 S. R. Diegelmann, J. M. Gorham and J. D. Tovar, J. Am. Chem. Soc., 2008, 130, 13840-13841.

134 H. Shao, T. Nguyen, N. C. Romano, D. A. Modarelli and J. R. Parquette, J. Am. Chem. Soc., 2009, 131, 16374-16376.

135 H. Shao, J. Seifert, N. C. Romano, M. Gao, J. J. Helmus, C. P. Jaroniec, D. A. Modarelli and J. R. Parquette, Angew. Chem., Int. Ed., 2010, 49, 7688-7691.

136 H. Shao and J. R. Parquette, Chem. Commun., 2010, 46, 4285-4287.

137 H. Shao, M. Gao, S. H. Kim, C. P. Jaroniec and J. R. Parquette, Chem. - Eur. J., 2011, 17, 12882-12885.

138 M. Ramanathan, L. K. Shrestha, T. Mori, Q. Ji, J. P. Hill and K. Ariga, Phys. Chem. Chem. Phys., 2013, 15, 10580-10611.

139 K. Ariga, M. Nishikawa, T. Mori, J. Takeya, L. K. Shrestha and J. P. Hill, Sci. Technol. Adv. Mater., 2019, 20, 51-95.

140 K. L. Morris, L. Chen, J. Raeburn, O. R. Sellick, P. Cotanda, A. Paul, P. C. Griffiths, S. M. King, R. K. O'Reilly and L. C. Serpell, Nat. Commun., 2013, 4, 1480.

141 A. Sarkar, T. Behera, R. Sasmal, R. Capelli, C. EmpereurMot, J. Mahato, S. S. Agasti, G. M. Pavan, A. Chowdhury and S. J. George, J. Am. Chem. Soc., 2020, 142, 11528-11539.

142 T. Fukui, S. Kawai, S. Fujinuma, Y. Matsushita, T. Yasuda, T. Sakurai, S. Seki, M. Takeuchi and K. Sugiyasu, Nat. Chem., 2017, 9, 493-499.

143 W. Wagner, M. Wehner, V. Stepanenko and F. Würthner, J. Am. Chem. Soc., 2019, 141, 12044-12054.

144 C. H. Chen, L. C. Palmer and S. I. Stupp, Nano Lett., 2018, 18, 6832-6841. 
145 J. R. Parquette and M. Ji, Chem. - Eur. J., 2020, 26, 8572-8578.

146 Y. Liu, K. Ai and L. Lu, Chem. Rev., 2014, 114, 5057-5115.

147 J. Ryu, P. Messersmith and H. Lee, ACS Appl. Mater. Interfaces, 2018, 10, 7523-7540.

148 A. J. Clancy, M. K. Bayazit, S. A. Hodge, N. T. Skipper, C. A. Howard and M. S. Shaffer, Chem. Rev., 2018, 118, 7363-7408.

149 C. Richard, F. Balavoine, P. Schultz, T. W. Ebbesen and C. Mioskowski, Science, 2003, 300, 775-778.

150 B. V. Derjaguin, N. V. Churaev, V. M. Muller and V. Kisin, The Derjaguin-Landau-Verwey-Overbeek (DLVO) Theory of Stability of Lyophobic Colloids, Surface Forces, Springer, Boston, MA, 1987, pp. 293-310.

151 V. Nicolosi, H. Cathcart, A. R. Dalton, D. Aherne, G. R. Dieckmann and J. N. Coleman, Biomacromolecules, 2008, 9, 598-602.

152 D. R. Samarajeewa, G. R. Dieckmann, S. O. Nielsen and I. H. Musselman, Carbon, 2013, 57, 88-98.

153 A. Ortiz-Acevedo, H. Xie, V. Zorbas, W. M. Sampson, A. B. Dalton, R. H. Baughman, R. K. Draper, I. H. Musselman and G. R. Dieckmann, J. Am. Chem. Soc., 2005, 127, 9512-9517.

154 C.-c. Chiu, M. C. Maher, G. R. Dieckmann and S. O. Nielsen, ACS Nano, 2010, 4, 2539-2546.

155 J. Montenegro, C. Vazquez-Vazquez, A. Kalinin, K. E. Geckeler and J. R. Granja, J. Am. Chem. Soc., 2014, 136, 2484-2491.

156 F. A. Mann, J. Horlebein, N. F. Meyer, D. Meyer, F. Thomas and S. Kruss, Chem. - Eur. J., 2018, 24, 12241-12245.

157 A. R. Thomson, C. W. Wood, A. J. Burton, G. J. Bartlett, R. B. Sessions, R. L. Brady and D. N. Woolfson, Science, 2014, 346, 485-488.

158 M. Ji, M. L. Mason, D. A. Modarelli and J. R. Parquette, Chem. Sci., 2019, 10, 7868-7877.

159 S. Manchineella and T. Govindaraju, RSC Adv., 2012, 2, 5539-5542.

160 S. Manchineella, V. Prathyusha, U. D. Priyakumar and T. Govindaraju, Chem. - Eur. J., 2013, 19, 16615-16624.

161 A. K. Dwivedi, M. Pandeeswar and T. Govindaraju, ACS Appl. Mater. Interfaces, 2014, 6, 21369-21379.

162 M. Ji, B. Daniels, A. Shieh, D. A. Modarelli and J. R. Parquette, Chem. Commun., 2017, 53, 12806-12809.

163 J. N. Israelachvili, Intermolecular and Surface Forces, Elsevier, USA, 3rd edn, 2011, pp. 528-530.

164 C. C. Cenker, S. Bucak and U. Olsson, Soft Matter, 2011, 7, 11548.

165 M. Ji, M. B. Dawadi, A. R. LaSalla, Y. Sun, D. A. Modarelli and J. R. Parquette, Langmuir, 2017, 33, 9129-9136.

166 P. G. Janssen, J. Vandenbergh, J. L. van Dongen, E. Meijer and A. P. Schenning, J. Am. Chem. Soc., 2007, 129, 6078-6079.

167 P. G. Janssen, S. Jabbari-Farouji, M. Surin, X. Vila, J. C. Gielen, T. F. de Greef, M. R. Vos, P. H. Bomans, N. A. Sommerdijk and P. C. Christianen, J. Am. Chem. Soc., 2009, 131, 1222-1231.
168 R. Ni and Y. Chau, J. Am. Chem. Soc., 2014, 136, 17902-17905.

169 R. Ni and Y. Chau, Angew. Chem., Int. Ed., 2017, 56, 9356-9360.

170 R. Ni and Y. Chau, Angew. Chem., Int. Ed., 2020, 59, 3578-3584.

171 R. Freeman, M. Han, Z. Álvarez, J. A. Lewis, J. R. Wester, N. Stephanopoulos, M. T. McClendon, C. Lynsky, J. M. Godbe, H. Sangji, E. Luijten and S. I. Stupp, Science, 2018, 362, 808-813.

172 M. R. Ghadiri, J. R. Granja, R. A. Milligan, D. E. McRee and N. Khazanovich, Nature, 1993, 366, 324-327.

173 M. R. Ghadiri, J. R. Granja and L. K. Buehler, Nature, 1994, 369, 301-304.

174 M. R. Ghadiri, Adv. Mater., 1995, 7, 675-677.

175 J. D. Hartgerink, J. R. Granja, R. A. Milligan and M. R. Ghadiri, J. Am. Chem. Soc., 1996, 118, 43-50.

176 K. Pandurangan, B. Roy, K. Rajasekhar, Y. V. Suseela, P. Nagendra, A. Chaturvedi, U. R. Satwik, N. A. Murugan, U. Ramamurty and T. Govindaraju, ACS Appl. Bio Mater., 2020, 3, 3413-3422.

177 S. Manchineella and T. Govindaraju, ChemPlusChem, 2017, 82, 88-106.

178 C. Balachandra and T. Govindaraju, J. Org. Chem., 2019, 85, 1525-1536.

179 S. Manchineella, N. A. Murugan and T. Govindaraju, Biomacromolecules, 2017, 18, 3581-3590.

180 R. Chapman, M. Danial, M. L. Koh, K. A. Jolliffe and S. Perrier, Chem. Soc. Rev., 2012, 41, 6023-6041.

181 M. Danial, C. M.-N. Tran, P. G. Young, S. Perrier and K. A. Jolliffe, Nat. Commun., 2013, 4, 1-13.

182 S. C. Larnaudie, J. C. Brendel, I. Romero-Canelón, C. Sanchez-Cano, S. Catrouillet, J. Sanchis, J. P. Coverdale, J.-I. Song, A. Habtemariam and P. J. Sadler, Biomacromolecules, 2018, 19, 239-247.

183 R. Chapman, K. A. Jolliffe and S. Perrier, Adv. Mater., 2013, 25, 1170-1172.

184 S. Catrouillet, J. C. Brendel, S. Larnaudie, T. Barlow, K. A. Jolliffe and S. Perrier, ACS Macro Lett., 2016, 5, 1119-1123.

185 J. Y. Rho, H. Cox, E. D. Mansfield, S. H. Ellacott, R. Peltier, J. C. Brendel, M. Hartlieb, T. A. Waigh and S. Perrier, Nat. Commun., 2019, 10, 1-9.

186 Q. Song, J. Yang, J. Y. Rho and S. Perrier, Chem. Commun., 2019, 55, 5291-5294.

187 N. T. Thanh, N. Maclean and S. Mahiddine, Chem. Rev., 2014, 114, 7610-7630.

188 E. Pazos, E. Sleep, C. M. Rubert Perez, S. S. Lee, F. Tantakitti and S. I. Stupp, J. Am. Chem. Soc., 2016, 138, 5507-5510.

189 Y. Yin, Z.-Y. Li, Z. Zhong, B. Gates, Y. Xia and S. Venkateswaran, J. Mater. Chem., 2002, 12, 522-527.

190 A. K. Awasthi, S. D. Bhagat, R. Ramakrishnan and A. Srivastava, Chem. - Eur. J., 2019, 25, 12905-12910.

191 J. R. Liebscher, R. Mrówczyński, H. A. Scheidt, C. Filip, N. D. Hădade, R. Turcu, A. Bende and S. Beck, Langmuir, 2013, 29, 10539-10548. 
192 H. Xu, X. Liu, G. Su, B. Zhang and D. Wang, Langmuir, 2012, 28, 13060-13065.

193 G. A. Hudalla, T. Sun, J. Z. Gasiorowski, H. Han, Y. F. Tian, A. S. Chong and J. H. Collier, Nat. Mater., 2014, 13, 829-836.

194 C. Mahato, A. Chatterjee and D. Das, Angew. Chem., Int. Ed., 2021, 60, 202-207.

195 S. Satagopan, Y. Sun, J. R. Parquette and F. R. Tabita, Biotechnol. Biofuels, 2017, 10, 175.

196 N. Wiradharma, Y. W. Tong and Y.-Y. Yang, Biomaterials, 2009, 30, 3100-3109.

197 P. Zhang, A. G. Cheetham, Y.-A. Lin and H. Cui, ACS Nano, 2013, 7, 5965-5977.

198 Y.-A. Lin, A. G. Cheetham, P. Zhang, Y.-C. Ou, Y. Li, G. Liu, D. Hermida-Merino, I. W. Hamley and H. Cui, ACS Nano, 2014, 8, 12690-12700.

199 H. Su, W. Zhang, H. Wang, F. Wang and H. Cui, J. Am. Chem. Soc., 2019, 141, 11997-12004.

200 H. Su, F. Wang, Y. Wang, A. G. Cheetham and H. Cui, J. Am. Chem. Soc., 2019, 141, 17107-17111.

201 Y. Sun, J. A. Kaplan, A. Shieh, H.-L. Sun, C. M. Croce, M. W. Grinstaff and J. R. Parquette, Chem. Commun., 2016, 52, 5254-5257.

202 H. A. M. Ardoña and J. D. Tovar, Chem. Sci., 2015, 6, 1474-1484. 203 J. López-Andarias, M. J. Rodriguez, C. Atienza, J. L. López, T. Mikie, S. Casado, S. Seki, J. L. Carrascosa and N. Martín, J. Am. Chem. Soc., 2015, 137, 893-897.

204 S. K. M. Nalluri, C. Berdugo, N. Javid, P. W. Frederix and R. V. Ulijn, Angew. Chem., 2014, 126, 5992-5997.

205 A. R. Hirst, S. Roy, M. Arora, A. K. Das, N. Hodson, P. Murray, S. Marshall, N. Javid, J. Sefcik and J. Boekhoven, Nat. Chem., 2010, 2, 1089-1094.
206 S. Fleming, S. Debnath, P. W. Frederix, N. T. Hunt and R. V. Ulijn, Biomacromolecules, 2014, 15 1171-1184.

207 C. Berdugo, S. K. M. Nalluri, N. Javid, B. Escuder, J. F. Miravet and R. V. Ulijn, ACS Appl. Mater. Interfaces, 2015, 7, 25946-25954.

208 Q. Zou, K. Liu, M. Abbas and X. Yan, Adv. Mater., 2016, 28, 1031-1043.

209 J. H. Kim, M. Lee, J. S. Lee and C. B. Park, Angew. Chem., 2012, 124, 532-535.

210 T. H. Han, W. J. Lee, D. H. Lee, J. E. Kim, E. Y. Choi and S. O. Kim, Adv. Mater., 2010, 22, 2060-2064.

211 I. Azuri, L. Adler-Abramovich, E. Gazit, O. Hod and L. Kronik, J. Am. Chem. Soc., 2014, 136, 963-969.

212 K. Tao, P. Makam, R. Aizen and E. Gazit, Science, 2017, 358, eaam9756.

213 M. Yemini, M. Reches, J. Rishpon and E. Gazit, Nano Lett., 2005, 5, 183-186.

214 M. Yemini, M. Reches, E. Gazit and J. Rishpon, Anal. Chem., 2005, 77, 5155-5159.

215 L. Adler-Abramovich, M. Badihi-Mossberg, E. Gazit and J. Rishpon, Small, 2010, 6, 825-831..

216 L. Adler-Abramovich, D. Aronov, P. Beker, M. Yevnin, S. Stempler, L. Buzhansky, G. Rosenman and E. Gazit, Nat. Nanotechnol., 2009, 4, 849-854.

217 C. A. Hunter, Angew. Chem., Int. Ed., 2004, 43, 5310-5324.

218 F. Biedermann and H.-J. R. Schneider, Chem. Rev., 2016, 116, 5216-5300.

219 M. D. Driver, M. J. Williamson, J. L. Cook and C. A. Hunter, Chem. Sci., 2020, 11, 4456-4466. 